\title{
Arqueologia regional e a construção das paisagens Guarani na margem esquerda do rio Paraná, Estado do Paraná, Brasil
}

\author{
Francisco Silva Noelli e Ângelo Alves Corrêa ${ }^{* *}$
}

Palavras-chave: Arqueologia Guarani; Manejo Agroflorestal; Padrão de Assentamento.

Keywords: Guarani Archaeology; Resource management; Settlement pattern.
Resumo: Este artigo é dedicado a mostrar alguns efeitos da presença Guarani na margem do rio Paraná, no Estado do Paraná, Brasil. Apresentamos aqui a compilação e uma análise dos dados arqueológicos com o objetivo de compreender os padrões de implantação dos sítios e apresentar aspectos do modelo de policultura agroflorestal usados para transformar meio ambiente em paisagem culturalmente modificada. A distribuição espacial das evidências arqueológicas associadas com dados históricos e etnográficos permitem concluir que os povos Guarani viveram (e ainda vivem) entre a foz do rio Iguaçu e a foz do rio Paranapanema por mais de 20 séculos, produzindo mudanças ambientais com suas técnicas de manejo agroflorestal.

Abstract: This article shows some effects of the Guarani presence in the left bank of the Paraná river, State of Paraná, Brazil. We present a compilation and analysis of archaeological data in order to understand the settlement patterns and aspects of Guarani agroforestry polyculture used to transform the environment in culturally modified landscape. The spatial distribution of archaeological evidence associated with historical and ethnographic data allow us to conclude that the Guarani lived (and still live) between the mouths of the Iguaçu River and the Paranapanema River for over 20 centuries, producing environmental changes with their resource management techniques agroforestry.

Recebido em 15 de abril de 2016. Aprovado em 10 de outubro de 2016.

\section{Introdução}

Nosso artigo é dedicado a mostrar alguns efeitos da presença Guarani na paisagem. Os registros arqueológicos associados com dados históricos e etnográficos permitem concluir que eles viveram (e ainda vivem) entre a foz do rio Iguaçu e a foz do rio Paranapanema por 20 séculos, o que gerou impactos na vegetação com as suas técnicas de manejo agroflorestal. Entretanto, as evidências botânicas de suas modificações da paisagem florestal desapareceram junto com a destruição da mata, restando hoje poucas áreas testemunho que permitiriam reconstruir parte desse modo de vida. O tipo de aldeamento que erigiam e o modo como formavam as suas áreas de policultura agroflorestal deixaram rastros muito sutis, sem monumentalidade, apenas perceptíveis com métodos arqueológicos e perguntas específicas. Elas são difíceis de responder hoje porque os investigadores que atuaram na região se dedicaram apenas à tarefa mais básica da arqueologia regional, que é a difícil tarefa de localizar e fazer as primeiras prospecções e registros sobre o contexto arqueológico. Portanto, neste estudo, tivemos por objetivo: 1) compilar e analisar os dados arqueológicos mais básicos para compreender os padrões de inserção dos sítios na paisagem; 2) tratar de aspectos do modelo de policultura agroflorestal e dos seus impactos na paisagem.

As margens do alto rio Paraná e dos seus afluentes, graças ao seu clima e biota favoráveis, nos últimos 10 milênios atraíram várias sociedades humanas. Na sua vasta bacia hidrográfica, existem inúmeros sítios arqueológicos e uma vasta quantidade de fontes históricas que registram a presença de vários povos indígenas e o processo de ocupação europeia (CNSA, 2016; NOELLI, 1999-2000; NOELLI, 2000; OLIVEIRA, 2002; BUENO; DIAS, 2015). Contudo, o estudo dos processos históricos, dos aspectos socioculturais e socioeconômicos está começando

\footnotetext{
* Prof. Aposentado Universidade Estadual de Maringá (UEM). E-mail: chico.noelli@gmail.com.

** Prof. Adjunto Universidade Federal do Piauí (UFPI). E-mail: angeloac33@gmail.com.
} 
e as informações ainda são limitadas. Como os ecossistemas ocupados e explorados por esses povos também são estudados pelas Ciências Naturais, cujas pesquisas ocorrem há várias décadas na Argentina, no Paraguai e no Brasil, ressaltamos que os conhecimentos gerados pelos geólogos, biólogos, palinólogos, físicos e químicos são indispensáveis para o reconhecimento das estratégias adaptativas na região.

\section{Área de estudo}

A área da análise deste trabalho compreende uma faixa de $400 \mathrm{Km}$ de comprimento por até $20 \mathrm{Km}$ de largura (média de $5 \mathrm{Km}$ ) ao longo do rio Paraná, entre a foz dos rios Iguaçu e Paranapanema. Essa faixa foi dividida em três partes: 1) Foz do Iguaçu-Foz do Piquiri; 2) Foz do Piquiri-Foz do Ivaí; 3) Foz do IvaíFoz do Paranapanema (Mapa Folhas A, B, C e D).

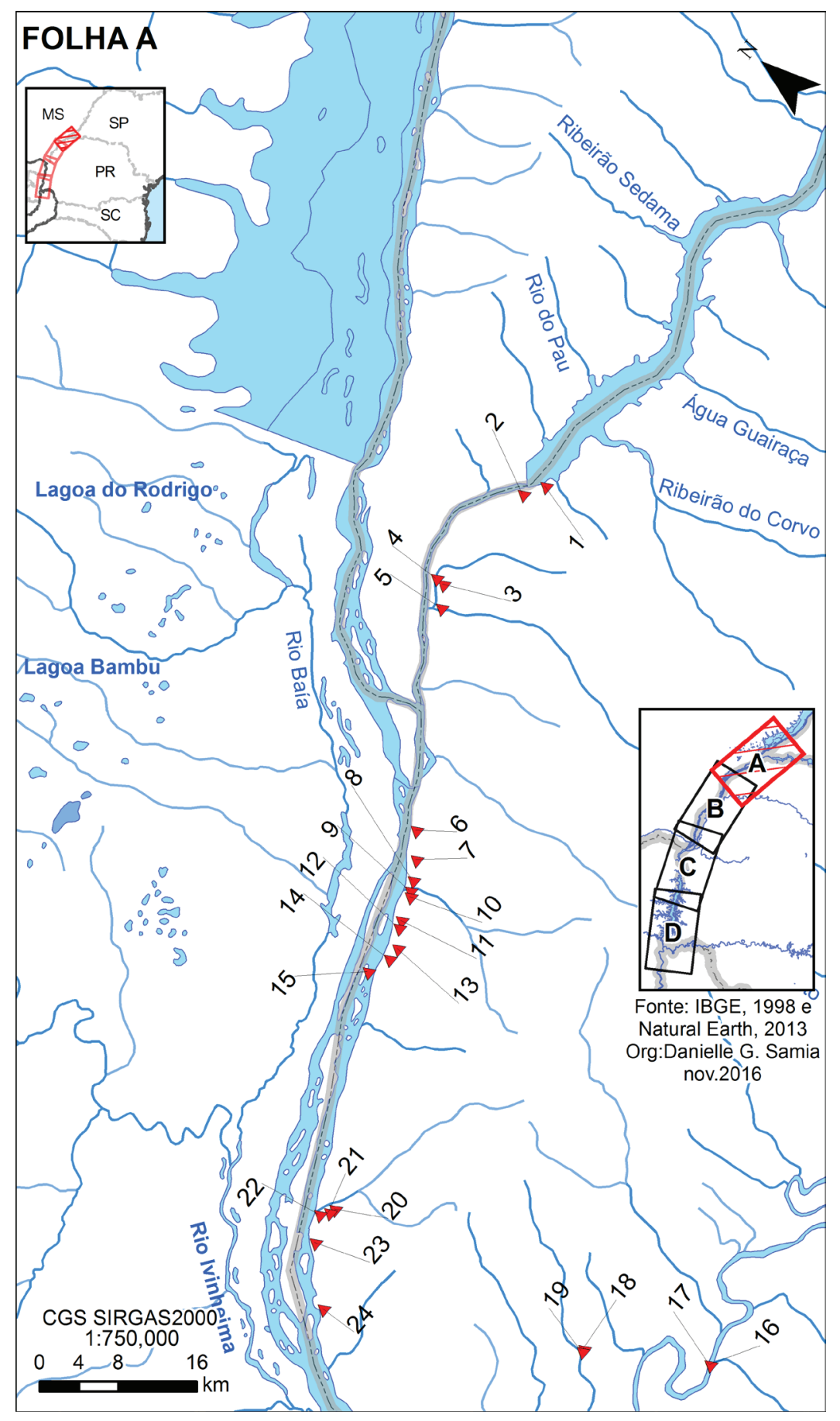

Mapa 1 - Sítios Guarani da área de estudo (Folhas A)

Fonte: IBGE (1998) e Natural Earth (2013). Organizado por Danielle G. Samia (2016). 


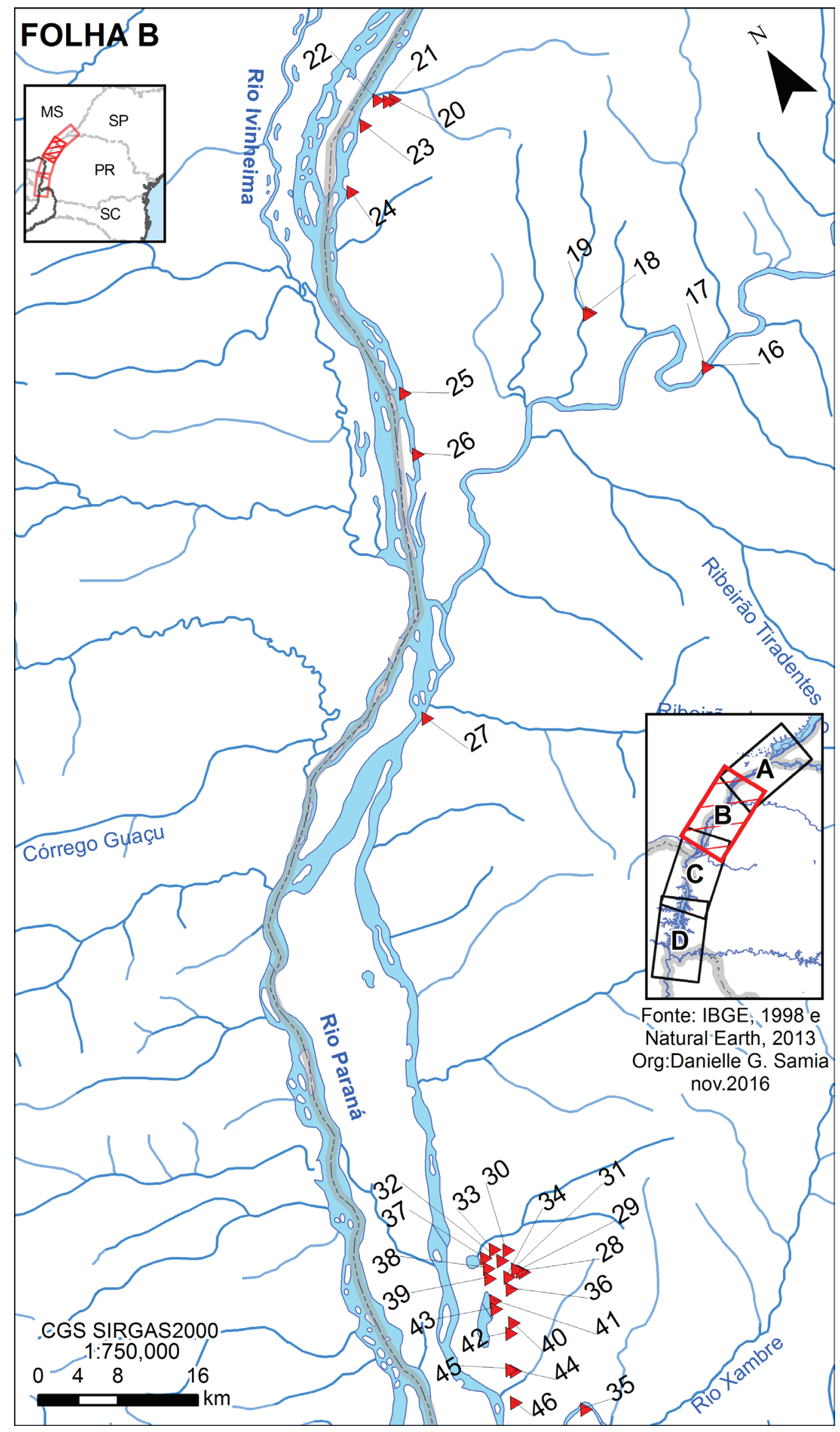

Mapa 1 - Sítios Guarani da área de estudo (Folhas B)

Fonte: IBGE (1998) e Natural Earth (2013). Organizado por Danielle G. Samia (2016). 


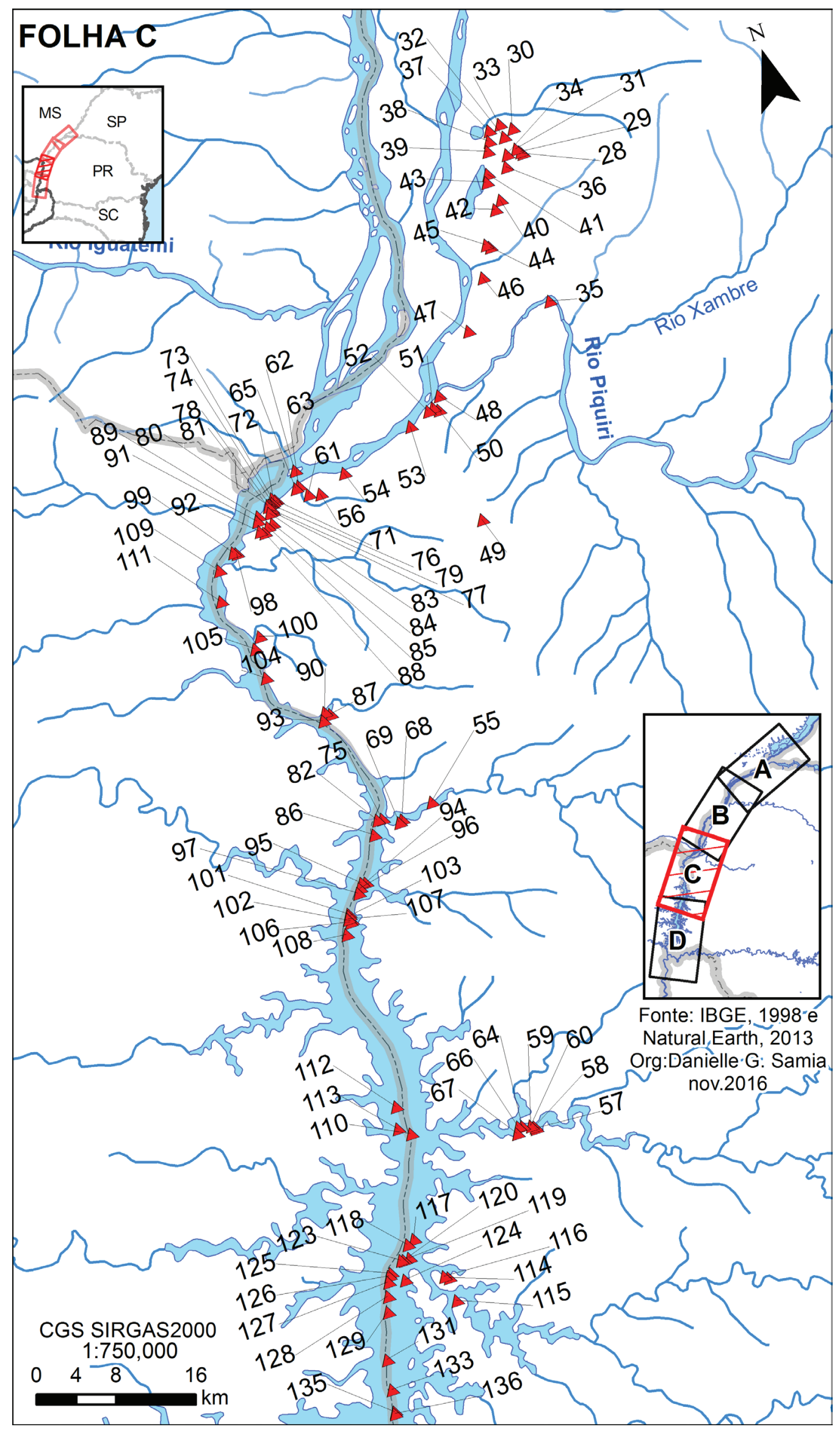

Mapa 1 - Sítios Guarani da área de estudo (Folhas C) 
Fonte: IBGE (1998) e Natural Earth (2013). Organizado por Danielle G. Samia (2016).

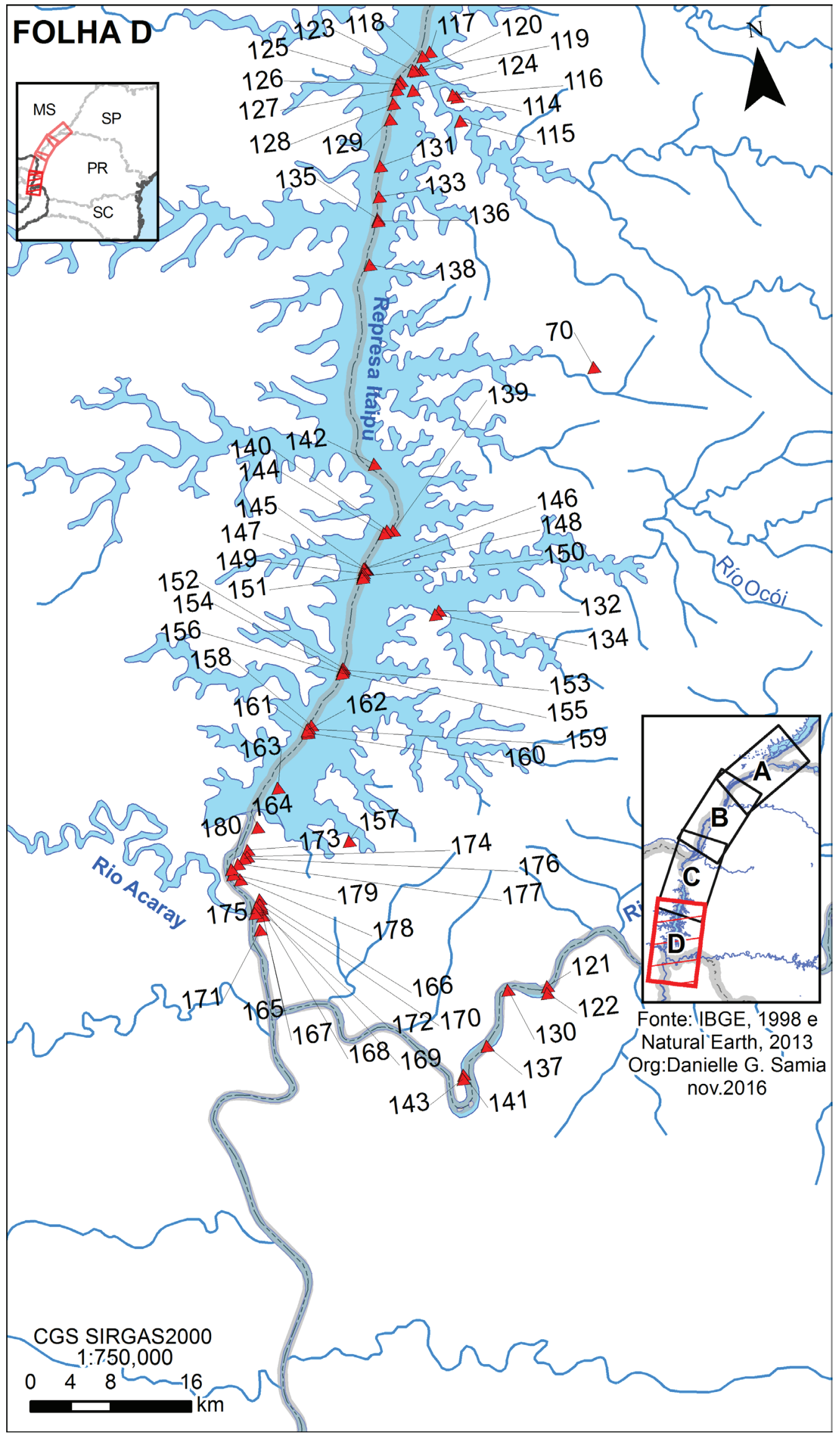


Mapa 1 - Sítios Guarani da área de estudo (Folhas D) Fonte: IBGE (1998) e Natural Earth (2013). Organizado por Danielle G. Samia (2016).

\section{Geologia}

O relevo possui formas tabulares onduladas com inclinação suave sendo interrompido, em alguns locais, pelas escarpas das "cuestas" da Serra Geral, a exemplo das cataratas de Foz do Iguaçu e do canyon submerso de Sete Quedas. A superfície da margem esquerda do rio Paraná, dividida proporcionalmente em duas partes no sentido norte-sul, é composta pelos basaltos da Formação Serra Geral (Foz do Iguaçu-Guaíra) e pelos arenitos da Formação Caiuá (Guaíra-Foz do Paranapanema). Nas encostas; predominam os solos podzólicos; já os latossolos e as areias quartzosas constituem os sedimentos mais comuns nas áreas de topo (SOUZA FILHO; STEVAUX, 1997). O Paraná apresenta-se nessa faixa como um rio de planície, com mais de 300 ilhas entrecortadas por canais, ladeados por várzeas e lagoas de extensão variável (STEVAUX, 1994).

\section{Hidrologia}

$\mathrm{Na}$ área deste estudo, o rio Paraná possui centenas de afluentes. Destacam-se os rios maiores, como o Ivinhema, Ivaí, Amambai e Piquiri (MAACK, 1981), que formam uma ampla rede de drenagem, a qual atraiu as sociedades humanas. São raros os sítios com mais del $\mathrm{km}$ do recurso, e a maioria dos sítios arqueológicos está a menos de $200 \mathrm{~m}$ de distância da água.

\section{Clima}

O clima do século 20 teve temperatura média de $21,5^{\circ} \mathrm{C}$ e precipitação média de $1.250 \mathrm{~mm}$ anuais. No sistema Köeppen, é classificado como Cfa, subtropical úmido mesotérmico, com verão quente. A temperatura mínima absoluta registrada para o século XX chegou a $-5,3^{\circ} \mathrm{C}$ em agosto de 1963, na cidade de Guaíra (MAACK, 1981). As flutuações climáticas globais do último milênio impuseram oscilações na temperatura do Cone Sul, com diminuição de 3 a $4{ }^{\circ} \mathrm{C}$ nas médias de alguns períodos (CIOCCALE, 1999). Várias oscilações climáticas deixaram marcas ao longo do Quaternário, cujo efeito sobre a vida das populações locais ainda está em pesquisa.

\section{Vegetação}

As formações florestais da área estão inseridas na região da floresta estacional semidecidual do bioma Mata Atlântica, cuja definição ecológica é condicionada pela dupla estacionalidade climática, uma tropical, com épocas de intensas chuvas de verão, e outra de estiagem no inverno (CAMPOS; SOUZA, 1997). A margem esquerda do rio Paraná pertence à formação denominada Floresta Estacional Semidecidual Aluvial, com planícies aluviais contínuas e descontínuas, sobre algumas ilhas do rio Paraná e margeando alguns rios na margem paranaense. Englobam agrupamentos florestais situados em solos frequentemente cobertos pelas águas, permitindo apenas o desenvolvimento de espécies arbóreas altamente seletivas, formando florestas muito abertas, com poucas espécies. As formações não florestais estão representadas por áreas de formações pioneiras com influência fluvial que, ocorrem ao longo das planícies fluviais e ao redor das depressões aluvionares (pântanos, lagunas e lagoas). Nos terrenos úmidos encharcados das margens, onde há maior sedimentação, encontrase a vegetação paludícula. Às margens das lagoas de várzea e canais secundários do alto rio Paraná, predominam espécies das Poaceae e Polygonaceae. Em trechos do canal principal, ocorrem praias arenosas com vegetação quase ausente. Os pulsos de inundação predominam no verão, condicionando a elevação dos cursos d'água, inundando a vegetação das áreas marginais. A influência da vegetação ripária sobre a biota é variável a cada fase do pulso hidrológico que controla a sedimentação. Nas fases das águas baixas, a vegetação ripariana comporta-se como um filtro entre os dois ecossistemas: terrestre e aquático. Muitas espécies relacionadas com a dieta natural de peixes herbívoros e de outras espécies de animais concentram-se nessa faixa do ecótono água/terra. O sistema de rio-planície, marcado pelo regime pulsátil de águas-altas que condiciona alagamentos em uma extensa área; a dispersão da 
vegetação, o histórico paleoclimático e a dinâmica do próprio sistema hidrográfico contribuem no mosaico vegetacional. Dessa forma, a área apresentase em diferentes níveis, com expressiva diversidade fisionômica, com espécies características da floresta estacional semidecidual, de várzeas e de cerrado, marcada grandemente pelos ecótonos transicionais.

\section{Arqueologia}

Os trechos Foz do Iguaçu-Foz do Piquiri e Foz do Ivaí-Foz do Paranapanema foram os mais pesquisados, enquanto o trecho Foz do PiquiriFoz do Ivaí somente atraíu os arqueólogos a partir da década de 1970. Embora tenha sido elaborada a planta baixa de Ciudad Real, não foi realizada nenhuma escavação ampla para contextualizar um assentamento e compreender como ele foi ocupado. A metodologia predominante é a abordagem aleatória e prospectiva de baixa intensidade, com levantamentos de superfície para localizar os sítios. Salientamos, ainda, que não foi realizado um programa intensivo para ampliar essa etapa prospectiva, tanto na superfície quanto nos $140 \mathrm{~cm}$ subsequentes, base dos contextos arqueológicos mais profundos registrados.

O trecho Foz do Iguaçu-Foz do Piquiri foi abordado desde 1892, através de ações colecionistas. A primeira atividade foi na área de foz do Iguaçu, por Ambrosetti (1895). A segunda, que inaugurou a pesquisa arqueológica, foi realizada por Watson (1947), na margem esquerda da foz do Piquiri, na Ciudad Real, um pueblo espanhol que durou 74 anos (1557-1631). Posteriormente, a cidade foi pesquisada em várias etapas a partir de 1958 (CHMYZ, 1976b; CHMYZ; CHMYZ; BROCHIER, 1999). Desde o final de 1968, Chmyz (1971) e Müller (1968) fizeram os primeiros levantamentos sistemáticos na área de Foz do Iguaçu, participando do Programa Nacional de Pesquisas Arqueológicas (PRONAPA, 1970). Os levantamentos prosseguiram no Parque Nacional do Iguaçú, na década de 1990, com novos sítios registrados por Chmyz e Miguel (1999). Com os preparativos para a instalação da hidrelétrica de Itaipu, a margem brasileira do trecho Foz do IguaçuFoz do Piquiri, teve novos levantamentos de Chmyz (1976a), que identificou 266 sítios, incluindo os da década de 1960 e mais alguns após 1982. Entre 1997 e 1999, na parte final do trecho, entre a cidade de Guaíra e a foz do rio Piquiri, assim como nas ilhas da área, foram registrados mais nove sítios por Francisco Noelli, mas sem nenhum tipo de prospecção ou escavação (SILVA; NOELLI, 2002). A margem direita do trecho, situada no Paraguai, também foi investigada no contexto de Itaipu, com o registro de 83 sítios arqueológicos (relatório Itaipu Binacional - Paraguai, Museo de la Tierra Guaraní). A margem do Mato Grosso do Sul foi parcialmente investigada por Chmyz (1983, p. 26-27), por equipes da Universidade Estadual de Maringá (UEM), da Universidade Federal do Mato Grosso do Sul (UFMS) e da Universidade Estadual do Mato Grosso do Sul (UEMS), com mais dez sítios registrados.

O trecho Foz do Piquiri-Foz do Ivaí foi escassamente investigado, com apenas 19 sítios arqueológicos registrados até o presente na margem paranaense (NOELLI; NOVAK; DOESWIJK, 2003). Destes, 18 estão concentrados no município de Altônia, com a maioria próxima da lagoa Xambrê. E, perto desta lagoa, Chmyz realizou escavações em um sítio (PR-XA-001; MACARI, 2013). Existem ainda oito indicações não confirmadas. No lado do Mato Grosso do Sul, o trecho também foi alvo de investigações isoladas, com mais cinco sítios registrados.

O trecho Foz do Ivaí - Foz do Paranapanema foi investigado em 1959. Blasi (1961) prospectou um sítio no município de Querência do Norte. Em meados de 1966 e 1967, início de 1970 e entre 1982 e 1991 Chmyz (1974, 1984, 1992) e Chmyz e Chmyz (1986) prospectaram e localizaram mais oito sítios em Diamante do Norte. No ano 2000, a equipe da UEM realizou apenas o registro preliminar de 29 sítios na Área de Proteção Ambiental Federal do Noroeste do Paraná (NOELLI et al., 2003), entre a barragem da hidrelétrica de Rosana (rio Paranapanema) e a foz do rio Ivaí. Esta APA está diretamente relacionada com as investigações na Margem do Mato Grosso do Sul, realizadas por Martins e Kashimoto (2000). Podemos considerar a área de ambas as margens como uma única área arqueológica devido às possíveis redes sociais e políticas entre seus ocupantes, ao menos entre os Guarani. Também possui estreitas relações 
com os territórios do baixo-médio rio Paranapanema (CHMYZ, 1977a, 1984, 1992; FACCIO, 1998; MORAIS, 2000). Na margem direita do rio Paraná, à jusante da foz do Paranapanema, estado do Mato Grosso do Sul, no mesmo trecho, foram localizados mais 11 sítios por Chmyz (1974), pela equipe da UEM (NOELLI et al., 2003) e por Kashimoto (1997).

As ilhas foram pouco investigadas, mas têm grande potencial para ocupação humana, tanto para subsistência quanto pelos aspectos defensivos. No caso Guarani, com base em informações históricas do século XVI descritas por Alonso de Santa Cruz, membro da expedição de Sebastião Caboto, eles praticavam a agricultura nas ilhas inundáveis da Foz do Rio da Prata. Podemos considerar que deviam sincronizar o plantio e a colheita com os ciclos de elevação/abaixamento do nível das águas.

Considerando a extensão de $400 \mathrm{Km}$ da área parcialmente pesquisada na margem do rio Paraná, os 323 sítios arqueológicos publicados são apenas a "ponta do iceberg" (conforme Mapa e Planilha 1, anexo A, para a localização dos sítios Guarani). E não incluídos nesse montante os sítios detectados em atividades de arqueologia de contrato, visto que não foram publicados e não se encontram disponíveis na base on-line do CNSA/IPHAN. Ainda há muito por fazer, tendo em vista o potencial das áreas já pesquisadas.

\section{Populações}

Classificamos as populações da região em função das evidências do registro arqueológico. Assim, em que pese o viés reducionista, ali viveram populações não ceramistas e ceramistas (as primeiras são usualmente denominadas como pré-ceramistas). Apesar de priorizarmos neste artigo os dados sobre as populações ceramistas Guarani, apresentamos nas planilhas as informações coletadas na bibliografia associadas aos povos pré-ceramistas e aos povos ceramistas Jê para fins comparativos.
As populações ceramistas possuem mais sítios e informações, sobretudo históricas, e são representadas por povos falantes das línguas Guarani, Kaingang e Xokleng que constituem dois grandes blocos culturais, de matriz Tupi (Guarani) e Jê (Kaingang e Xokleng), cuja origem remonta ao médio Amazonas para os primeiros e o Brasil central para os demais (BROCHADO, 1984; NOELLI, 1996, 1998a, 1999, 2004). A partir de processos de colonização começaram a ocupar o sul do Brasil antes de 2.200 AP - datações da Tabela 1, conforme Chmyz $(1981,1983)$.

Os assentamentos Guarani eram constituídos de casas comunais, abrigando cada uma até várias centenas de pessoas. O principal elemento diagnóstico dessas populações é a cerâmica, cujo padrão formal caracteriza os estilos tecnológicos das suas artesãs, amplamente difundido na porção meridional da bacia do Paraná (LA SALVIA; BROCHADO, 1989; NOELLI, 2004; CORRÊA, 2014).

No caso Guarani, as camadas de Terra Preta Arqueológica (TPA), em meio aos solos podzólicos, atestam permanência de longo prazo e grande processamento de materiais orgânicos vegetais nas aldeias. A agricultura de coivara praticada por essas populações causava alterações ambientais devido à constante abertura de clareiras para inserção de roças, especialmente, se considerarmos que reproduziram seu sistema agroflorestal por mais de 2.000 anos nas margens do rio Paraná e dos seus afluentes; afinal o sistema é similar ao dos povos Amazônicos, segundo Noelli $(1993,2006)$ e Balée $(1994,2000)$.

Outro aspecto que merece destaque na ocupação regional Guarani de longa duração é a introdução de espécies de outras regiões. Eles disseminaram um "pacote de plantas" nas regiões que colonizaram, assim como fizeram com a sua cultura material. Podemos afirmar que, ao mesmo tempo em que disseminaram este "pacote", também adotavam novas espécies nas áreas que iam dominando. 
Tabela 1 - Datações dos sítios Guarani da área Foz do Iguaçu-Foz do Paranapanema

\begin{tabular}{|c|c|c|c|c|}
\hline Município & Sítio & $\begin{array}{c}\text { Base da camada } \\
\text { arqueológica }(\mathbf{m})\end{array}$ & Datas AP & Código Lab. \\
\hline Itaipulândia & $\mathrm{PR}-\mathrm{Fl}-140$ & 0,2 & $2010 \pm 75^{\star}$ & Sl 5028 \\
\hline Foz do Iguaçu & $\mathrm{PR}-\mathrm{Fl}-97$ & 0,2 & $1295 \pm 60^{*}$ & Sl 5016 \\
\hline São Miguel do Iguaçu & $\mathrm{PR}-\mathrm{Fl}-142$ & 0,2 & $1455 \pm 60^{*}$ & Sl 5033 \\
\hline Santa Helena & $\mathrm{PR}-\mathrm{Fl}-118$ & 0,2 & $1625 \pm 60^{*}$ & Sl 5021 \\
\hline São Miguel do Iguaçu & $\mathrm{PR}-\mathrm{Fl}-99$ & 0,15 & $1635 \pm 70^{*}$ & Sl 5019 \\
\hline Foz do Iguaçu & $\mathrm{PR}-\mathrm{Fl}-22$ & 0,3 & $234 \pm 80^{*}$ & Sl 5015 \\
\hline Guaíra & $\mathrm{PR}-\mathrm{FO}-06$ & 0,3 & $85 \pm 60$ & SI 5041 \\
\hline Itaipulândia & PR - FI - 104 & 0,2 & $85 \pm 75$ & SI 5030 \\
\hline Foz do Iguaçu & PR $-\mathrm{FI}-98$ & 0,2 & $190 \pm 95$ & SI 5018 \\
\hline Itaipulândia & PR - FI - 142 & 0,2 & 195 & SI 5031 \\
\hline Santa Helena & PR - FI - 118 & 0,15 & $205 \pm 80$ & SI 5022 \\
\hline Foz do Iguaçu & PR - FI - 97 & 0,2 & $255 \pm 80$ & SI 5017 \\
\hline Foz do Iguaçu & PR - FI - 99 & 0,15 & $1565 \pm 70$ & SI 5019 \\
\hline Santa Helena & $\mathrm{PR}-\mathrm{Fl}-118$ & 0,18 & $340 \pm 60$ & Sl 5023 \\
\hline São Miguel do Iguaçu & $\mathrm{PR}-\mathrm{Fl}-142$ & 0,15 & $395 \pm 60$ & Sl 5034 \\
\hline Itaipulândia & $\mathrm{PR}-\mathrm{Fl}-104$ & 0,13 & $415 \pm 75$ & Sl 5032 \\
\hline Guaíra & $\mathrm{PR}-\mathrm{FO}-03$ & 0,2 & $490 \pm 60$ & Sl 5040 \\
\hline Diamante do Norte & $\mathrm{PR}-\mathrm{NL}-07$ & 0,35 & $530 \pm 55$ & Sl 6400 \\
\hline Santa Helena & $\mathrm{PR}-\mathrm{Fl}-127$ & 0,15 & $590 \pm 55^{\star}$ & Sl 5024 \\
\hline Foz do Iguaçu & $\mathrm{PR}-\mathrm{Fl}-82$ & 0,25 & $595 \pm 200$ & Sl 5047 \\
\hline Itaipulândia & $\mathrm{PR}-\mathrm{Fl}-103$ & 0,15 & $600 \pm 60$ & Sl 5029 \\
\hline Foz do Iguaçu & $\mathrm{PR}-\mathrm{Fl}-100$ & 0,15 & $625 \pm 55$ & Sl 5020 \\
\hline Itaipulândia & $\mathrm{PR}-\mathrm{Fl}-140$ & 0,12 & $745 \pm 75$ & Sl 5027 \\
\hline Guaíra & $\mathrm{PR}-\mathrm{FO}-04$ & 0,15 & $760 \pm 40$ & Sl 5039 \\
\hline Guaíra & $P R-F O-20$ & 0,3 & $700 \pm 55$ & SI 5036 \\
\hline
\end{tabular}

Fonte: Elaborada pelos autores (2016)

\section{Localização dos sítios arqueológicos no Trecho foz do Iguaçu - Foz do Paranapanema}

É importante ressaltarmos que essa é a primeira análise regional do padrão de inserção das populações Guarani que ocuparam a margem esquerda do rio Paraná, no trecho Foz do IguaçuFoz do Paranapanema. As tabelas informam, para eventuais comparações, sobre as ocupações não Guarani (mas não incluímos a análise desses dados nos mapas e no texto a seguir). São os seguintes os dados selecionados para definir alguns aspectos sobre o padrão de inserção: 1) compartimento topográfico; 2) distância da água mais próxima; 3) distância do rio Paraná; 4) cor do solo arqueológico; 5) posição da base da camada arqueológica; 6) altitude do sítio em relação ao nível do mar.

\section{Compartimento topográfico}

Trata-se do perfil do local de implantação do sítio no relevo. Dividimos o perfil em: 1) topo; 2) encosta; 3) terraço; 4) topo/encosta; 5) encosta/terraço; 6) ilha (Tabela 2). A análise do compartimento topográfico revelou que a encosta é o local de preferência, seguida do topo e da transição topo/encosta. Juntos, os três compartimentos representam $81,01 \%$ da amostra. O terraço e a transição terraço/encosta foram menos relevantes, perfazendo $11,75 \%$ do total. As ilhas apareceram em pouca quantidade, devido à falta de pesquisa, 
mas é possível que sua ocupação tenha sido comum. O predomínio das ocupações de encosta revela uma preocupação com a drenagem. Manter as habitações e as demais áreas de atividade da aldeia com pouca umidade e fora de locais alagadiços foi opção deliberada. Não há dados sobre o ângulo de inclinação dos compartimentos topográficos, fato que reduz a capacidade dessa análise.

Tabela 2 - Compartimento Topográfico

\begin{tabular}{|c|c|c|c|c|c|c|c|c|c|c|}
\hline $\begin{array}{l}\text { Compartimento } \\
\text { Topográfico }\end{array}$ & Geral & $\%$ & Vinitu & Humaitá & Ipacaraí & Icaraíma & Tatuí & Itaguajé & Jê & Guarani \\
\hline Encosta & 212 & 65,63 & 19 & 37 & 3 & 2 & 4 & 4 & 19 & 124 \\
\hline Topo & 39 & 12,07 & 2 & 7 & 2 & & 7 & & 4 & 17 \\
\hline Terraço & 33 & 10,21 & 2 & 6 & 1 & & 2 & & 13 & 9 \\
\hline Topo/Encosta & 12 & 3,71 & 1 & & & & & & 2 & 9 \\
\hline Terraço/Encosta & 5 & 1,54 & 1 & & & & & & 2 & 2 \\
\hline Ilha & 5 & 1,54 & & & & & & & 2 & 3 \\
\hline $\mathrm{Nd}$ & 17 & 5,26 & & 4 & & & & & & 13 \\
\hline Total & 323 & 100 & 25 & 54 & 6 & 2 & 13 & 4 & 42 & 177 \\
\hline
\end{tabular}

Fonte: Elaborada pelos autores (2016)

\section{Distância da água mais próxima}

A maioria dos sítios está perto da água, recurso abundante na região (Tabela 3). A proximidade pesou na decisão da implantação em todos os períodos, pois 86,98\% estão até $300 \mathrm{~m}$ do recurso. Destes, $64,08 \%$ estão até $100 \mathrm{~m}$ de distância.

Tabela 3 - Distância da água mais próxima

\begin{tabular}{|c|c|c|c|c|c|c|c|c|c|c|}
\hline Distância (m) & Geral & $\%$ & Vinitu & Humaitá & Ipacaraí & Icaraíma & Tatuí & Itaguajé & Jê & Guarani \\
\hline $0-100$ & 207 & 64,08 & 23 & 37 & 5 & 2 & 8 & 4 & 32 & 96 \\
\hline $101-200$ & 46 & 14,24 & & 9 & 1 & & 1 & & 8 & 28 \\
\hline 201-300 & 28 & 8,66 & & 7 & & & 4 & & 1 & 15 \\
\hline $301-400$ & 1 & 0,3 & & 1 & & & & & & \\
\hline $401-500$ & 3 & 0,9 & & & & & & & & 3 \\
\hline $501-600$ & 2 & 0,6 & & & & & & & & 2 \\
\hline $601-700$ & 2 & 0,6 & & & & & & & & 2 \\
\hline $901-1.000$ & 1 & 0,3 & & & & & & & & 1 \\
\hline N. d. & 33 & 10,21 & 2 & & & & & & 1 & 30 \\
\hline Total & 323 & 100 & 25 & 54 & 6 & 2 & 13 & 4 & 42 & 177 \\
\hline
\end{tabular}

Fonte: Elaborada pelos autores (2016)

\section{Distância do rio Paraná}

Essa distância serve para reconhecer a relação dos sítios com o grande rio, bem como para determinar o acesso à água, aos recursos de subsistência e de matéria-prima e à navegação (Tabela 4). A distância pode ser analisada junto com a "água mais próxima" (Tabela 3), revelando a constante preocupação de instalar-se perto do recurso e do grande rio, pois $51,06 \%$ estão até $500 \mathrm{~m}$ do rio Paraná. 
Tabela 4 - Distância do rio Paraná

\begin{tabular}{|c|c|c|c|c|c|c|c|c|c|c|}
\hline Distância (m) & Geral & $\%$ & Vinitu & Humaitá & Ipacaraí & Icaraíma & Tatuí & Itaguajé & Jê & Guarani \\
\hline $0-100$ & 59 & 18,26 & 1 & & & & 5 & 3 & 4 & 46 \\
\hline $101-200$ & 48 & 14,86 & 1 & 1 & & & 2 & & 5 & 39 \\
\hline $201-300$ & 34 & 10,52 & 3 & 4 & 1 & & & 1 & 1 & 24 \\
\hline $301-400$ & 11 & 3,4 & 1 & 4 & 1 & 1 & & & 1 & 3 \\
\hline $401-500$ & 13 & 4,02 & 1 & 1 & 1 & 1 & 1 & & & 8 \\
\hline $501-600$ & 5 & 1,54 & & 2 & & & & & & 3 \\
\hline $601-700$ & 6 & 1,85 & 1 & 1 & & & & & 2 & 2 \\
\hline $701-800$ & 3 & 0,9 & & & & & & & 1 & 2 \\
\hline $801-900$ & 4 & 1,2 & & & & & & & & 4 \\
\hline $901-1.000$ & 4 & 1,2 & & 1 & & & 1 & & & 2 \\
\hline $1.001-2.000$ & 10 & 3,09 & & 2 & & & 1 & & & 7 \\
\hline $2.001-3.000$ & 7 & 2,16 & 1 & 2 & & & & & 3 & 1 \\
\hline $3.001-4.000$ & 17 & 5,26 & 1 & 7 & & & 1 & & 8 & \\
\hline $4.001-5.000$ & 19 & 5,88 & 5 & 5 & 1 & & & & 5 & 3 \\
\hline $5.001-6.000$ & 11 & 3,4 & 1 & 5 & & & & & 3 & 2 \\
\hline $6.001-7.000$ & 13 & 4,02 & 3 & 1 & 2 & & 1 & & 3 & 3 \\
\hline $7.001-8.000$ & 11 & 3,4 & 4 & 3 & & & & & 2 & 2 \\
\hline $8.001-9.000$ & 9 & 2,78 & & 5 & & & & & & 4 \\
\hline $9.001-10.000$ & 10 & 3,09 & & 3 & & & 1 & & 3 & 3 \\
\hline $10.001-13.000$ & 12 & 3,71 & 1 & 7 & & & & & 1 & 3 \\
\hline N.d. & 17 & 5,26 & 1 & & & & & & & 16 \\
\hline Total & 323 & 100 & 25 & 54 & 6 & 2 & 13 & 4 & 42 & 177 \\
\hline
\end{tabular}

Fonte: Elaborada pelos autores (2016).

\section{Cor do solo arqueológico ${ }^{2}$}

A cor do solo revela, a priori, dois aspectos da atividade humana no contexto arqueológico: duração da ocupação e intensidade das atividades domésticas. Destacamos que, quanto maior é a semelhança entre a cor dos solos arqueológicos e do seu entorno natural, menor foi a duração do assentamento ou menos intensas foram as atividades domésticas, com baixo processamento e descarte de materiais orgânicos, e que, em contrapartida, quanto maiores as diferenças entre a cor do solo arqueológico e o seu entorno natural, mais tempo durou a ocupação e mais intensas foram as atividades domésticas e maior foi o volume de descarte de materiais orgânicos. Em ambos os casos, as variações nas cores significam que há diferentes traços químicos de elementos orgânicos e inorgânicos manipulados pelos ocupantes do sítio arqueológico. Todavia, nos solos onde não é visível a diferença de cor, a análise geoquímica pode detectar evidências de atividades domésticas, provavelmente realizadas por um período de tempo inferior ao necessário para modificar a coloração dos sedimentos (KERN, 1996). O compartimento topográfico é outro fator importante, pois a inclinação do terreno associada a processos erosivos pluviais, eólicos e antrópicos pós-deposicionais pode causar a remoção da camada com a cor alterada. Como a maioria dos sítios do rio Paraná está em encostas ou topos com algum grau de inclinação, provavelmente vários perderam as camadas superiores devido a processos erosivos ampliados por desmatamento.

Para formar um centímetro de espessura de TPA é necessário bastante tempo com contínua ação humana de descarte de material orgânico com composições que variam em cada assentamento, com características particulares e únicas. Por exemplo, Smith (1980) sugeriu que para formar $1 \mathrm{~cm}$ desse tipo de solo são necessários dez anos, o que implica considerarmos que, para a formação de $10 \mathrm{~cm}$, 
passariam 100 anos. Erickson (2003) estimou que, para formar 75-90 cm de TPA, a taxa é de 0,008 a 0,1 $\mathrm{cm} /$ ano. Logo, é possível aldeias cujas sedes duraram pelo menos 100 anos no mesmo local (possivelmente muito mais tempo, sendo a TPA indicador direto de sedentarismo, de impacto ambiental e das práticas de manejo agroflorestal realizadas continuamente). Infelizmente, ainda não dispomos de dados específicos sobre a espessura das camadas arqueológicas de todos os sítios no rio Paraná; contudo, para vários sítios Guarani, há informações que indicam espessuras médias entre 10 e 20 cm (CHMYZ, 1971, 1974, 1976, 1983, 1984), chegando até $50 \mathrm{~cm}$ (BLASI, 1961). A Tabela 5 apresenta as cores dos solos de vários sítios arqueológicos. A ausência de TPA em sítios Guarani deve-se ao tipo de ocupação e a processos erosivos pós-deposicionais.

Tabela 5 - Cor do solo arqueológico

\begin{tabular}{|c|c|c|c|c|c|c|c|c|c|c|}
\hline Cor do solo & Geral & $\%$ & Vinitu & Humaitá & Ipacaraí & Icaraíma & Tatuí & Itaguajé & Jê & Guarani \\
\hline Amarelo & 3 & 0,9 & & & 1 & & & & & 2 \\
\hline Amarelo-claro & 2 & 0,6 & & & & & 1 & & & 1 \\
\hline Amarelo- avermelhado & 14 & 4,33 & 1 & 3 & 2 & & & & 4 & 4 \\
\hline Cinza & 1 & 0,3 & & & & & & & & 1 \\
\hline Cinza-amarelado & 4 & 1,2 & & & & & & & 2 & 2 \\
\hline Cinza-claro & 16 & 4,95 & & 1 & & & 1 & & 13 & 1 \\
\hline Cinza-escuro & 11 & 3,4 & & 2 & & & 2 & & & 7 \\
\hline Cinza-escuro/ marrom & 2 & 0,6 & & 2 & & & & & & \\
\hline \multicolumn{11}{|l|}{ Avermelhado } \\
\hline Marrom & 2 & 0,6 & 1 & 1 & & & & & & \\
\hline Marrom-amarelado & 2 & 0,6 & 1 & & & & & & & 1 \\
\hline Marrom-avermelhado & 105 & 32,5 & 16 & 35 & 2 & 1 & 4 & & 17 & 30 \\
\hline Marrom-claro & 15 & 4,64 & & 3 & 1 & 1 & 2 & 4 & & 4 \\
\hline Marrom-escuro & 43 & 13,31 & 6 & 6 & & & 3 & & 3 & 25 \\
\hline TPA & 51 & 15,78 & & & & & & & 1 & 50 \\
\hline N.d. & 52 & 16,09 & & 1 & & & & & 2 & 49 \\
\hline Total & 323 & 100 & 25 & 54 & 6 & 2 & 13 & 4 & 42 & 177 \\
\hline
\end{tabular}

Fonte: Elaborada pelos autores (2016) conforme Chmyz (1976, 1977, 1978, 1979, 1980, 1981, 1983$).$

\section{Posição da base da camada arqueológica}

A posição da base da camada arqueológica em relação à superfície do solo atual indica que $41,46 \%$ dos sítios estão entre 11 e $50 \mathrm{~cm}$ de profundidade (Tabela 6). Mas, como não há dados sobre a espessura da camada de ocupação da maioria dos sítios pesquisados, ainda não podemos definir os padrões sedimentares pós-deposicionais.

Se observarmos a Tabela 6, veremos que os pisos dos sítios Jê e Guarani, presentes na região a partir de $2.010 \mathrm{AP}$, predominam entre 10 e $30 \mathrm{~cm}$ de profundidade. Entre o nível de ocupação dos povos ceramistas e dos pré-ceramistas, em geral, eventualmente há uma camada estéril em termos arqueológicos, variando de poucos centímetros a 1 $\mathrm{m}$. Essa camada normalmente apresenta sedimentos eólicos com rara presença de vestígios orgânicos, devendo corresponder ao segundo evento árido que ocorreu entre 3.500 e $2.500 \mathrm{AP}$ no alto rio Paraná (STEVAUX; SOUSA FILHO; JABUR, 1997; STEVAUX; SANTOS, 1998). Os últimos séculos do período de aridez foram de transição para um clima mais úmido, quando a cobertura vegetal arbórea começou a predominar; e o final do período coincidiu com o início da ocupação dos povos ceramistas e o desaparecimento dos sítios pré-ceramistas nas proximidades do rio Paraná. Os dados permitem deduzir que essas mudanças climáticas têm estreita 
relação com os processos de ocupação humana no continente. O período entre 4.000 e $2.000 \mathrm{AP}$ corresponde a uma grande explosão demográfica na Amazônia (BROCHADO, 1984; CORRÊA, 2014), com diversos povos ceramistas e agricultores expandindo-se geograficamente e ocupando o leste da América do Sul. Duas frentes dessas expansões alcançaram o sul do Brasil entre 2.500 e 2.000 AP, quando as populações Guarani começaram a ocupar os estados do Mato Grosso do Sul, extremo oeste de São Paulo, Paraná, Santa Catarina, Rio Grande do Sul, Uruguai, o nordeste da Argentina e o Paraguai oriental. A outra frente (de povos Jê) ocupou o leste de São Paulo e parte do Paraná, Santa Catarina e Rio Grande do Sul.

Outro aspecto que precisa ser investigado é o início da ocupação Guarani e o tempo de ocupação dos sítios. Chmyz (1983, p. 102-103), que obteve todas as datações do trecho em análise, não aceitou as datas de alguns sítios Guarani, justificando que elas não concordavam com os parâmetros estratigráficos definidos por ele. Isto é, em alguns casos, encontrou datas mais antigas em profundidades menores que alguns níveis com datas mais recentes e, em outros casos, encontrou datas mais recentes abaixo de níveis mais antigos (Tabela 1). Chmyz baseou sua opinião no princípio do PRONAPA, de que a ocupação dos sítios sempre seria de curta duração (EVANS; MEGGERS, 1965).

Com as novas abordagens desenvolvidas para o estudo dos solos, como no caso das TPAs e nos casos de sítios submetidos a várias datações, como fizeram Martins, Kashimoto e Tatumi (1999) e Martins e Kashimoto (2000), consideramos que o princípio do PRONAPA está obsoleto. Além disso, as datas de Chmyz não foram obtidas nas mesmas colunas estratigráficas, mas em áreas diferentes dos sítios pesquisados, abrindo a perspectiva para adotarmos outra interpretação sobre a idade dos sítios. Considerando que: 1) $1 \mathrm{~cm}$ de espessura de TPA pode levar dez anos para se formar; 2) os sítios podem ser reocupados sem que haja uma notável diferença estratigráfica ou de evidências arqueológicas; 3 ) a estratigrafia pode apresentar variações em termos de espessura e composição em um único sítio. Então, podemos aceitar as datas rejeitadas por Chmyz, pois elas estão dentro dos limites temporais da ocupação Guarani no alto rio Paraná (NOELLI, 1999-2000; CORRÊA, 2014; BONOMO et al., 2015).

Tabela 6 - Posição da base da camada arqueológica

\begin{tabular}{|c|c|c|c|c|c|c|c|c|c|c|}
\hline $\begin{array}{l}\text { Base da Camada } \\
\text { Arqueológica - } \mathrm{cm}\end{array}$ & Geral & $\%$ & Vinitu & Humaitá & Ipacaraí & Icaraíma & Tatuí & Itaguajé & Jê & Guarani \\
\hline $0-10$ & 7 & 2,16 & 1 & & & & & & 1 & 5 \\
\hline $11-15$ & 47 & 14,55 & & 1 & & & & & 11 & 35 \\
\hline $16-20$ & 24 & 7,43 & 1 & & & & & & 5 & 18 \\
\hline $21-25$ & 11 & 3,4 & & 1 & & & & & & 10 \\
\hline $26-30$ & 19 & 5,88 & 2 & 1 & & & 1 & & & 15 \\
\hline $36-40$ & 15 & 4,64 & 3 & & 3 & & 2 & & 1 & 6 \\
\hline 41-45 & 9 & 2,78 & & 7 & & & 2 & & & \\
\hline $46-50$ & 9 & 2,78 & 1 & 4 & 1 & & 1 & 1 & & 1 \\
\hline 51-55 & 1 & 0,3 & 1 & & & & & & & \\
\hline $56-60$ & 3 & 0,9 & 1 & & & & 1 & & 1 & \\
\hline $61-70$ & 2 & 0,6 & 1 & 1 & & & & & & \\
\hline $71-80$ & 6 & 1,85 & 1 & & & & 1 & 3 & 1 & \\
\hline $90-1.0$ & 1 & 0,3 & 1 & & & & & & & \\
\hline $1-1.40$ & 1 & 0,3 & & & & & 1 & & & \\
\hline N.d. & 168 & 52,01 & 12 & 39 & 2 & 2 & 4 & & 22 & 87 \\
\hline Total & 323 & 100 & 25 & 54 & 6 & 2 & 13 & 4 & 42 & 177 \\
\hline
\end{tabular}

Fonte: Elaborada pelos autores (2016). 


\section{Altitude do sítio em relação ao nível do mar}

Os sítios arqueológicos mais elevados acima do nível do mar estão a $362 \mathrm{~m}$ (Tabela 7), enquanto que os mais baixos estão na cota 100, na área de
Foz do Iguaçu. A altitude, associada com a latitude próxima do Trópico de Capricórnio, resulta em clima ameno com temperatura média anual de $21,5^{\circ} \mathrm{C}$ e precipitação média de $1250 \mathrm{~mm}$ anuais, classificado no sistema Köppen como Cfa, subtropical úmido mesotérmico, com verão quente.

Tabela 7 - Altitude do sítio em relação ao nível do mar (A. S. N. M.)

\begin{tabular}{|c|c|c|c|c|c|c|c|c|c|c|}
\hline A. S. N. M. & Geral & $\%$ & Vinitu & Humaitá & Ipacaraí & Icaraíma & Tatuí & Itaguajé & Jê & Guarani \\
\hline $100-110$ & 4 & 1,2 & & 1 & & 1 & & & & 2 \\
\hline $111-120$ & 3 & 0,9 & & & & & & & & 3 \\
\hline $121-130$ & 11 & 3,4 & 1 & 5 & 1 & 1 & & & & 3 \\
\hline $131-140$ & 7 & 2,16 & & 2 & & & & & & 5 \\
\hline $141-150$ & 14 & 4,33 & & 1 & 1 & & 1 & & & 11 \\
\hline $151-160$ & 11 & 3,4 & & 1 & 1 & & 1 & & & 8 \\
\hline $161-170$ & 14 & 4,33 & 2 & 3 & & & & & 1 & 8 \\
\hline $171-180$ & 14 & 4,33 & 1 & & & & 2 & & 7 & 4 \\
\hline $181-190$ & 26 & 8,04 & 6 & 1 & & & & & 5 & 14 \\
\hline $191-200$ & 34 & 10,52 & 3 & 8 & 1 & & 1 & & 10 & 11 \\
\hline $201-210$ & 61 & 18,88 & 6 & 23 & 2 & & 1 & & 9 & 20 \\
\hline $211-220$ & 40 & 12,38 & 2 & 9 & & & 5 & & 5 & 19 \\
\hline $221-230$ & 22 & 6,81 & 3 & & & & 2 & & 4 & 13 \\
\hline $240-259$ & 15 & 4,64 & 1 & & & & & 4 & 1 & 9 \\
\hline $260-274$ & 18 & 5,57 & & & & & & & & 18 \\
\hline $280-295$ & 8 & 2,47 & & & & & & & & 8 \\
\hline $298-362$ & 4 & 1,2 & & & & & & & & 4 \\
\hline N.d. & 17 & 5,26 & & & & & & & & 5 \\
\hline Total & 323 & 100 & 25 & 54 & 6 & 2 & 13 & 4 & 42 & 177 \\
\hline
\end{tabular}

Fonte: Elaborada pelos autores (2016).

\section{Alterações ambientais produzidas pelos Guarani}

Trataremos apenas das alterações ambientais realizadas pelos Guarani. Todavia, consideramos que os pré-ceramistas também promoveram modificações na vegetação, pelo manejo de algumas espécies ao longo de 6 mil anos ou mais. $\mathrm{O}$ mesmo ocorreu com os Jê, que praticavam agricultura e manejavam diversas espécies. No caso Guarani; as informações são basicamente históricas; no entanto, a sua qualidade e quantidade são notáveis, permitindo que se construa um modelo de ocupação do espaço, certamente comum a todos os grupos que se espalharam por uma vasta área na bacia do Paraná (NOELLI, 1993, 1996, 1998a, 1999-2000).
A unidade territorial básica Guarani é o tekohá, o espaço de domínio de uma aldeia, composto pela área das habitações, áreas de roça, áreas de roça em pousio, áreas de pesca, áreas de caça, trilhas, cemitérios, porto das canoas, sempre instalada em clareiras no interior da floresta. As habitações de um assentamento Guarani eram situadas em uma clareira ou distribuídas em várias clareiras contíguas. À medida que a população crescia, as aldeias aumentavam em área ou se desdobravam. Eventualmente, cisões dividiam os habitantes em um ou mais grupos que iam ocupar áreas manejadas na periferia dos tekohás, formando novas aldeias, mais distanciadas daquelas que lhes deram origem. A base da organização social é a família nuclear (pai, mãe, filhos), com um tamanho médio de 6 membros, 
mas uma família poligâmica poderia compor agrupamentos de até 40,50 ou mais membros. As famílias nucleares, por sua vez, associavam-se ao redor de uma pessoa com prestígio, criando a família extensa, unidade social que formava a "casa grande" e que podia alcançar dimensões de até $50 \mathrm{~m}$ de comprimento por $18 \mathrm{~m}$ de largura. Uma aldeia podia ter uma ou várias famílias extensas, especialmente nos pontos mais estratégicos da região. As aldeias formavam redes de aliança para fins sociais, econômicos etc. As análises mais conservadoras, com base na documentação histórica, estimam que o tamanho da população Guarani no oeste do Estado do Paraná, no primeiro quartel do século XVII, alcançaria até 1.500 .000 pessoas (MELIÀ, 1986). Mas é possível que houvesse três vezes ou mais indivíduos, pois Melià não considerou plenamente os eventos do século XVI e início do XVII, quando epidemias devastaram de modo incalculável os indígenas da região.

Essa explicação sobre as aldeias e sua organização resume o contexto social relacionado ao modelo agroflorestal padrão Guarani, entre Foz do Iguaçu e a foz do Paranapanema. Com certeza, ao longo de no mínimo 2.000 anos eles modificaram a fitogeografia da região, introduzindo um "pacote" com inúmeras plantas domesticadas e semidomesticadas trazidas da Amazônia, Chaco, Pantanal e alto rio Paraná (Tabela 8). José Cândido Stevaux (com. pessoal, 2001) informa que as primeiras análises de colunas polínicas de áreas próximas da Foz do Paranapanema revelaram presença de mandioca (Maniot esculenta Crantz) em 1.700 AP. Deverão ser descobertos pólens ainda mais antigos, pois os Guarani estavam ali antes de 2.000 AP.

Considerando as redes de troca Guarani, é provável que eles introduziram ali espécies do sul do Brasil, da mata atlântica e do Pampa (NOELLI, 1998b). Também realizaram manejos de certas espécies, concentrando-as para aumentar sua produção, como a erva-mate (Ilex paraguariensis), a araucária (Araucaria angustifolia) e frutíferas, como a jaboticaba (Plinia trunciflora). Várias palmeiras eram cultivadas como alimento e matérias-primas, principalmente para cobertura das habitações. $\mathrm{Na}$ literatura e nos relatos dos moradores atuais da beira do rio Paraná e afluentes, há ou havia remanescentes de concentrações de palmito com vários hectares no meio da floresta, a maioria certamente antropogênica, relictos de manejos Guarani.

O locus básico da agricultura Guarani era a roça de coivara. Mas cultivavam outros espaços, como o quintal das casas, as trilhas, as clareiras abertas por árvores tombadas, à beira dos cursos d'água, das áreas alagadiças e nas ilhas. As roças pertenciam às famílias extensas, divididas em espaços menores sob a responsabilidade de famílias nucleares afins. Em média, a cada seis pessoas correspondia cerca de 2,5 hectares de área na roça nova. Uma família extensa de 600 pessoas podia ter roças de até 250 hectares de clareiras abertas para cultivar todos os anos. É importante notar que as roças novas eram abertas anualmente e, conforme o tipo de solo, servindo aos cultivos básicos (Tabela 8), durante vários anos. Mas, podiam produzir indefinidamente, uma vez que em algumas roças eram cultivadas espécies para vários fins, muitas delas arbustivas perenes ou arbóreas (alimento, matéria-prima, medicinal). Uma família extensa podia ter várias roças simultâneas, de diferentes idades, produzindo espécies distintas, bem como podiam manter as áreas mais antigas em pousio por 20, 30 ou mais anos, onde também explorariam com coleta produtos diversos. Nas roças mais novas, eram cultivadas aproximadamente 139 cultivares distintos do "pacote básico" (Tabela 8):

Esse modelo causou alterações antrópicas significativas, ignoradas pelos botânicos que pesquisam o trecho Foz do Iguaçu - Foz do Paranapanema, pois eles normalmente consideram apenas as mudanças humanas após a década de 1950. A abertura anual de clareiras, associada à prática da policultura agroflorestal e ao transplante sistemático de várias espécies, resultava em alteração fitossociológica, fitogeográfica, o que explicaria as adventícias. A repetição do manejo Guarani por 2.000 anos (mais o manejo das populações anteriores) modificou as características "naturais" da fisionomia da vegetação próxima do rio Paraná e dos seus afluentes, ampliando a variedade das espécies. $\mathrm{E}$ as modificações não ocorriam apenas nas roças. A floresta era entrecortada por redes de trilhas, mantidas abertas para conectar os diversos locais de assentamento e exploração dentro dos tekohás. 
Um exemplo contemporâneo desse tipo de manejo exemplifica o potencial da intervenção antropogênica na biodiversidade, conforme observou Posey (1987) entre os Gorotire-Kayapó:

[...] as margens desses caminhos conformam zonas de cultivo. Com efeito, é comum encontrar faixas limpas de árvores com $4 \mathrm{~m}$ de largura. Torna-se difícil calcular a extensão dessas trilhas... Uma estimativa conservadora avalia em $500 \mathrm{~km}$ a extensão dos caminhos abertos pelos gorotire [...] medindo cerca de 2,5 m de largura. Como se vê, a área remanejada é ponderável. As margens das trilhas são plantadas com numerosas variedades de inhames, batata doce, marantáceas, cupá, zingiberáceas, aráceas e outras plantas tuberosas não identificadas. Centenas de plantas medicinais e árvores frutíferas também contribuem para diversificar essa flora plantada. Vejamos um exemplo. O levantamento feito numa trilha de $3 \mathrm{~km}[\ldots]$ constatou a existência de: 185 árvores plantadas, representando pelo menos 15 espécies diferentes; 2) aproximadamente 1.500 plantas medicinais pertencentes a um número indeterminado de espécies; 3 ) cerca de 3.500 plantas alimentícias de um número igualmente não identificado de espécies. (POSEY, 1987, p. 177).

Tabela 8 - Amostragem de algumas espécies da agricultura Guarani

\begin{tabular}{|c|c|c|c|c|}
\hline & Nome Popular & Nome Guarani & Nome Científico & No de Cultivares \\
\hline \multicolumn{5}{|l|}{ Tuberosas } \\
\hline & Mandioca & Mandio & Manihot esculenta & 24 \\
\hline & Batata-doce & Jety & Ipomoea batatas & 21 \\
\hline & Batata "inglesa" & Maky & Solanum tuberosum & 1 \\
\hline & Cará & Kara & Dioscorea spp & 9 \\
\hline & Feijão macuco & Mbakuku & Pachyrrhizus erosus & 3 \\
\hline & Mangarito & Tajao & Xanthosoma sagittifolium & 2 \\
\hline & Araruta & Akuti & Maranta arundinacea & 1 \\
\hline & Batatinha & Makyxi & Oxalis spp & 4 \\
\hline & Piriquiti & Mbery sai'yu & Canna glauca & 1 \\
\hline \multicolumn{5}{|l|}{ Graníferas } \\
\hline & Piriquiti & Mbery sai'yu & Canna glauca & 1 \\
\hline & Feijão & Kumanda & Phaseolus spp & 16 \\
\hline & Amaranto & Ka’aruru & Amaranthus spp & 4 \\
\hline & Quina & Ka'are & Chenopodium spp & $?$ \\
\hline & Amendoim & Manduvi & Arachis hypogaea & 7 \\
\hline & Tremoceiro & Manduvira & Lupinus spp & 1 \\
\hline & Feijão-guandu & Kumanda yvyra'i & Cajanus spp & 1 \\
\hline & & Cumandá cha’i & Strophostyles diversifolia & 1 \\
\hline & Fava de rama & Kumanda usu & Canavalia spp & 1 \\
\hline & Lágrima de N. Sra. & Mbaguero & Coix lacrima-jobi & 1 \\
\hline \multicolumn{5}{|l|}{ Curcubitáceas } \\
\hline & Abóbora cheirosa & Andai & Cucurbita moschata & 4 \\
\hline & Moranga & Kurapep囚 & Cucurbita maxima & 1 \\
\hline & Cruá & Kurugua & Sicana odorifera & 1 \\
\hline
\end{tabular}

Fonte: Noelli (1994). 


\section{Espécies manejadas pelos Guarani}

A análise sistemática das informações Guarani permite estabelecer uma lista de espécies para ser comparada aos levantamentos botânicos. Desconhecemos o número total de plantas exploradas ou conhecidas por eles, mas Gatti (1985) conseguiu identificar cerca de 1500 espécies para o Paraguai e países limítrofes. Outros pesquisadores, em diferentes lugares da Argentina, Brasil e Uruguai, também revelaram listas extensas (NOELLI, 1993). A lista de Gatti, mesmo incompleta e defasada em relação aos modernos avanços e redefinições taxonômicas, e necessitando de novas pesquisas etnográficas, pode ser comparada às listas botânicas. No caso do rio Paraná, escolhemos, para fins comparativos, a flora registrada perto da foz do Paranapanema, nos municípios de Porto Rico e Taquaruçu (CAMPOS; SOUZA, 1997; SOUZA; CISLINSKI; ROMAGNOLO, 1997; ROMAGNOLO; SOUZA, 2000; CAMPOS, 1997). Foram identificadas 541 espécies fanerogâmicas, mas há indícios de que a quantidade seja maior, ultrapassando as 800 espécies em uma área que sofreu grande modificação botânica em função do desmatamento, da agricultura, do extrativismo de drogas medicinais e da pecuária.

A comparação entre as listas dos botânicos e dos indígenas mostrou que os Guarani exploravam ou conheciam pelo menos 432 espécies, correspondendo a $79,85 \%$ das 541 identificadas até o presente em Porto Rico (Tabela 9):

Tabela 9 - Funções das espécies vegetais na cultura Guarani

\begin{tabular}{lcc}
\hline Função & Quantidade & Total \% \\
\hline Alimento & 69 & 12,75 \\
Medicinal & 212 & 39,18 \\
Matéria-prima & 135 & 24,94 \\
Sem função determinada & 191 & 35,30 \\
Sem nome Guarani & 107 & 19,77 \\
Total Porto Rico & 541 & 100 \\
\hline
\end{tabular}

Fonte: Elaborada pelos autores (2016).

É possível verificar que os Guarani tinham diversas funções para a flora. O número elevado de espécies sem nome e sem função deve-se às lacunas de informação nas fontes publicadas. Provavelmente, a exemplo de outros povos Tupi (BALÉE, 1994), os Guarani nomeariam um número maior de espécies que as utilizadas. Devia ocorrer o mesmo com a função das espécies, dividida somente em três itens devido ao espaço disponível nesse trabalho, pois as subdivisões ultrapassariam os 60 itens caso empregássemos as categorias classificatórias e funcionais nativas (NOELLI, 1993).

A função mais comum é a medicinal: 39,18\% do total. O percentual elevado demonstra a extensão do conhecimento botânico Guarani e, também, a preocupação em sanar problemas de saúde (NOELLI, 1998c). A segunda função é a matéria-prima, com $24,94 \%$ do total. As espécies úteis nessa função são numerosas e, considerando outros estudos sobre a cultura material Guarani (NOELLI, 1993), serão ampliadas à medida que o levantamento botânico da área prosseguir.

As plantas usadas como alimento correspondem a $12,75 \%$ do total. Se considerássemos a classificação nativa, teríamos de incluir as plantas que serviam de alimento para os animais, ampliando em muito a quantidade de plantas úteis para a alimentação. Associando essas 69 espécies com as plantas típicas de roça apresentadas na Tabela 8 e com os animais que eram consumidos, podemos verificar que a lista de alimentos Guarani era extensa e bem distribuída ao longo do ano.

A exemplo de outras áreas com pesquisa arqueológica (PIPERNO; PEARSALL, 1998), é possível que das 434 espécies conhecidas ou usadas pelos Guarani existam vestígios na área de Porto Rico, tanto nos antigos locais de habitação e das utilizadas como roça. As 434 espécies conhecidas até o presente devem ser consideradas como de grande potencial para serem encontradas nas futuras pesquisas. Os contextos arqueológicos poderão ter vestígios polínicos e pedaços vegetais pequenos, a exemplo do que se encontrou em outras partes da América do Sul. E coprólitos, cálculos dentários e elementos químicos nos ossos humanos também revelarão o consumo de plantas. As áreas de TPA dos contextos arqueológicos Guarani, pela alta concentração de resíduos orgânicos, são candidatas para revelar a relação entre humanos e vegetação. 
As TPAs também são o banco de informações sobre fauna regional, pois elas são as lixeiras das aldeias e, consequentemente, contêm uma grande quantidade de restos alimentares.

\section{Considerações finais}

As evidências arqueológicas e históricas revelam que a geologia, o clima e os ecossistemas da área de influência do rio Paraná favoreceram o assentamento humano. Desde $8.000 \mathrm{AP}$, as populações humanas encontraram ali os meios para viver e reproduzir suas sociedades. No entanto, em face do estado inicial das pesquisas, tivemos condições de perceber apenas a ponta do iceberg.

Os dados mostram ocupação contínua entras as sociedades pré-ceramistas e ceramistas. Os primeiros perduraram cerca de 6.000 anos, enquanto os ceramistas viveram ali por 1.800 anos, tendo sua reprodução social e histórica interrompida pela presença europeia, cujas guerras, epidemias e estrutura socioeconômica causaram um colapso demográfico de grande magnitude, com o desaparecimento de pelos menos 1 milhão de pessoas no início do século XVII. Posteriormente, retornaram a partir do século XVIII. Como vimos no caso Guarani, tanta gente, por tanto tempo, deve ter causado modificações ambientais relevantes e, possivelmente, também devem ter feito ou causado algumas no terreno que ainda desconhecemos, como a abertura de canais como no Curutuba (José Cândido Stevaux, com. pessoal 1998).

Por outro lado, é importante questionarmos: quais as mudanças e dificuldades impostas pelo ambiente e pelas mudanças climáticas? Quais as consequências dessas mudanças na vida cotidiana, na cultura, na alimentação e na saúde dessas populações? Houve, de fato, mudanças significativas? Os eventos de aridez, especialmente entre $3.500 \mathrm{e}$ 2.000 AP reduziram a densidade demográfica da região? Quais as relações entre o final do período de aridez, ao redor de $2.000 \mathrm{BP}$, e o início da colonização Guarani e Jê no sul do Brasil?

Como o alto rio Paraná é uma área de grande potencial para a pesquisa arqueológica, devido às suas características naturais que atraíram diversas populações ao longo dos milênios, a crescente quantidade de pesquisas realizadas pelas geociências e pela botânica, sem dúvida, deverá contribuir decisivamente para a compreensão e conhecimento da vida humana naqueles paleoambientes.

Agradecimentos: A Igor Chmyz, pela longa pesquisa arqueológica nos rios Paraná e Paranapanema, cujos resultados publicados foram amplamente utilizados neste trabalho; à Iriana Tanaka, pelos comentários e pelas sugestões sobre a vegetação; à Dirce C. Kern, pelas informações sobre a formação da TPA; à Mirian Carbonera, editora da Revista Caderno do CEOM, pelo convite para participarmos neste volume. Evidentemente, as ideias expressas desse artigo são de nossa responsabilidade.

\section{Notas}

1 As datas com asterisco não foram aceitas pelo pesquisador que as obteve (CHMYZ, 1983). Mas, considerando as datações feitas por Kashimoto, Martins e Tatumi (1999) na área de UH Primavera e as demais datas para o sul do Brasil (BONOMO et al., 2015; CORRÊA, 2014), tais datas são aceitáveis.

2 As referências da Munsell Color Chart não estão sendo usadas pelo fato de que elas não foram empregadas pelos arqueólogos que pesquisaram na área tratada neste artigo.

\section{Referências}

AMBROSETTI, J. B. Los cementerios de prehistóricos del alto Paraná (Misiones). Boletín del Instituto Geográfico Argentino, v. 16, p. 227-257, 1895.

BALÉE, W. Footprints in the forest. New York: Columbia University Press, 1994.

Antiquity of traditional knowledge in Amazonia: The Tupí-Guaraní Family and Time. Ethnohistory, v. 47, n. 2, p. 399-422, 2000.

BLASI, O. Algumas notas sobre a jazida arqueológica de Três Morrinhos - Querência do Norte - Rio Paraná. Boletim Paranaense de Geografia, v. 2-3, p. 49-78, 1961.

BONOMO, M.; ANGRIZANI, R.; APOLINAIRE, E.; A model for the Guaraní expansion in the La 
Plata Basin and littoral zone of southern Brazil. Quaternary International, v. 356, p. 54-73, 2015.

BROCHADO, J. P. An ecological model of the spread of pottery and agriculture into Eastern South America. 1984. 574 f. PhD Thesis (Doctorate in Philosophy and Anthropology) - University of Illinois at Urbana-Champaign, Urbana-Champaign, 1984.

BUENO, L.; DIAS, A. Povoamento inicial da América do Sul: contribuições do contexto brasileiro. Estudos Avançados, v. 29, n. 83, p. 119-147, 2015.

CAMPOS, J. Análise dos desflorestamentos, estrutura dos fragmentos de florestas e avaliação do banco de sementes do solo da ilha Porto Rico na planície de inundação do alto rio Paraná, Brasil. 1997. 248 f. Tese (Doutorado em Ecologia) Universidade Estadual de Maringá, Maringá, 1997.

CAMPOS, J. C.; SOUSA, M. C. Vegetação. In: VAZZOLER, A. E. A. M.; AGOSTINHO, A. A.; HAHN, N. S. (Ed.). A Planície de inundação do alto rio Paraná: aspectos físicos, biológicos e socioeconômicos. Maringá: Eduem, 1997. p. 331-342.

CIOCCALE, M. A. Climatic fluctuations in the Central Region of Argentina in the last 1000 years. Quaternary International, v. 62, p. 35-47, 1999.

CNSA. Cadastro Nacional de sítios Arqueológicos. Instituto do Patrimônio Histórico e Artístico Nacional. Disponível em: $<$ www.iphan.gov.br/cnsa $>$. Acesso em: 16 jun. 2016.

CHMYZ, I. Pesquisas Arqueológicas no Médio e Baixo Rio Iguaçu, Paraná - PRONAPA 4. Publicações Avulsas do Museu Paranaense Emílio Goeldi, n. 15, p. 87-114, 1971.

Dados Arqueológicos do Baixo Rio Paranapanema e do Alto Rio Paraná - PRONAPA 5. Publicações Avulsas do Museu Paranaense Emílio Goeldi, n. 26, p. 67-90, 1974.

Arqueologia e História da vila espanhola de Ciudad Real do Guairá. Cadernos de Arqueologia, v. 1, p. 7-103, 1976a.

Projeto arqueológico Itaipu (1975-1983):

Vol 1. Curitiba: Convênio Itaipú/IPHAN, 1976b.
Pesquisas Paleoetnográficas efetuadas no vale do rio Paranapanema. Paraná/São Paulo. Boletim de Psicologia e Antropologia, v. 5, p. 1-248, 1977a.

Projeto arqueológico Itaipu (1975-1983):

Vol. 2. Curitiba: Convênio Itaipú/IPHAN, 1977b.

Projeto arqueológico Itaipu (1975-1983):

Vol. 3. Curitiba: Convênio Itaipú/IPHAN, 1978.

Projeto arqueológico Itaipu (1975-1983):

Vol. 4. Curitiba: Convênio Itaipú/IPHAN, 1979.

Projeto arqueológico Itaipu (1975-1983):

Vol. 5. Curitiba: Convênio Itaipú/IPHAN, 1980.

Projeto arqueológico Itaipu (1975-1983):

Vol. 6. Curitiba: Convênio Itaipú/IPHAN, 1981.

Estado atual das pesquisas arqueológicas na margem esquerda do rio Paraná (Projeto arqueológico Itaipu). Estudos Brasileiros, v. 8, n. 13, Curitiba, p. 5-39, 1982.

Projeto arqueológico Itaipu (1975-1983):

Vol. 7. Curitiba: Convênio Itaipú/IPHAN, 1983.

Projeto Arqueológico Rosana-Taquaruçu. Curitiba: UFPR-CESP, 1984.

Relatório de atividades do projeto arqueológico Rosana - Taquaruçu. Curitiba: CESP/ FUNDAR, 1992.

.; CHMYZ, J. C. G. Datações radiométricas em áreas de salvamento arqueológico. Revista do Centro de Ensino e Pesquisas Arqueológicas, v. 5, Curitiba, p. 69-77, 1986. .; BROCHIER, L. Levantamento

dos bens arqueológicos associados às ruínas de Ciudad Real del Guayrá. Curitiba: CEPA/UFPR, 1999.

; MIGUEL, R. Relatório Técnico sobre a Arqueologia e a Etno-História da área do Parque Nacional do Iguaçu. Curitiba: IBAMA/FUNPAR, 1999. 
CORRÊA, A. A. Pindorama de mboîa e îakaré: continuidade e mudança na trajetória das populações Tupi. 462 f. Tese (Doutorado em Arqueologia) Programa de Pós-Graduação em Arqueologia, Museu de Arqueologia e Etnologia, Universidade de São Paulo, São Paulo, 2014.

ERICKSON, C. Historical ecology and future explorations. In: LEHMANN, J.; KERN, D. C.; GLASER, B.; WOODS, W. I. (Ed.). Amazonian black earths: origins, properties and management. Leyden: Kluwer, 2003. p. 455-500.

EVANS, C.; MEGGERS, B. Guia para prospeç̧ão arqueológica no Brasil. Belém: Museu Paraense Emílio Goeldi, 1965.

FACCIO, N. Arqueologia do cenário das ocupações horticultoras da Capivara, Baixo Paranapanema SP. 1998. 322 f. Tese (Doutorado em Arqueologia) - Programa de Pós-Graduação em Arqueologia, Universidade de São Paulo, São Paulo, 1998.

GATTI, C. Enciclopédia Guarani-Español de conocimientos Paraguayos. Asunción: Arte Nuevo, 1985.

IBGE. Hidrografia Base Contínua 250 mil. 2013. Disponível em: <http://www.ibge.gov.br/>. Acesso em: 16 jun. 2016.

KASHIMOTO, E. M. Variáveis ambientais e arqueológicas no alto Paraná. 1997. 259 f. Tese (Doutorado em Arqueologia) - Programa de PósGraduação em Arqueologia, Universidade de São Paulo, São Paulo, 1997.

KERN, D. C. Geoquímica e Pedogeoquímica de sítios arqueológicos com terra preta na Floresta Nacional de Caxiuanã (Portel-Pará). 1996. $421 \mathrm{f}$. Tese (Doutorado em Geologia) - Programa de PósGraduação em Geologia, Universidade Federal do Pará, Belém, 1996.

LA SALVIA, F; BROCHADO, J. P. Cerâmica guarani. Porto Alegre: Posenato Arte \& Cultura, 1989.

MAACK, R. Geografia do Paraná. Rio de Janeiro: José Olympio, 1981.
MACARI, B. P. Arqueoentomologia: Um estudo de caso Tupiguarani, Altônia, Paraná, Brasil. 2013. 68 f. Dissertação (Mestrado em Zoologia) - Programa de Pós-Graduação em Zoologia, Universidade Federal do Paraná, Curitiba, 2013.

MARTINS, G. R.; KASHIMOTO, E. M. Arqueologia do contexto do rio Jauru (MT). Impactado pelo gasoduto Bolívia - Mato Grosso. Revista do Museu de Arqueologia e Etnologia, v. 10, p. 121-143. 2000.

.; KASHIMOTO, E. M.; TATUMI, S. H. Datações arqueológicas em Mato Grosso do Sul. Revista do Museu de Arqueologia e Etnologia, v. 9, p. 73-93, 1999.

MELIÀ, B. El Guaraní conquistado y reducido. Asunción: CEADUC, 1986.

MORAIS, J. L. Arqueologia da Região Sudeste. Revista USP, n. 44. p. 194-217, 2000.

MÜller, A. C. Proposição de manejo para o Parque Nacional do Iguaçu. 1978. 200 f. Dissertação (Mestrado em Ciências) - Programa de PósGraduação em Ciências, Universidade Federal do Paraná, Curitiba, 1978.

NATURAL EARTH. Divisão Territorial America Latina e Território Nacional. 2013. Disponível em: $<$ http://www.naturalearthdata.com>. Acesso em: 15 jun. 2016.

NOELLI, F. S. Sem Tekohá não há Tekó (em busca de um modelo etnoarqueológico da subsistência e da aldeia Guarani aplicado a uma área de domínio no delta do Jacuí-RS). 1993. 389 f. Dissertação (Mestrado em História) - Programa de PósGraduação em História, Pontifícia Universidade Católica do Rio Grande do Sul, Porto Alegre, 1993.

NOELLI, F. S. El Guaraní agricultor. Acción, v. 177, p. 17-23, 1994.

As hipóteses sobre o centro de origem e as rotas de expansão dos Tupi. Revista de Antropologia, v. 39, n. 2, p. 7-53, 1996.

The Tupi: explaining origin and expansion in terms of Archaeology and Historical Linguistics. Antiquity, v. 72, n. 277, p. 648-663, 1998a. 
Múltiplos usos de espécies vegetais pela farmacologia Guarani através de informações históricas. Diálogos, n. 2, p. 177-199, 1998b.

Aportes históricos e etnológicos para o reconhecimento da classificação Guarani de comunidades vegetais no século XVII. Fronteiras Revista de História, v. 2, n. 4, p. 275-296, 1998c.

Repensando os rótulos e a História dos Jê no sul do Brasil a partir de uma interpretação interdisciplinar. Revista do Museu de Arqueologia e Etnologia, suplemento, v. 1, p. 218-269, 1999.

ocupação humana na região sul do Brasil: Arqueologia, debates e perspectivas - 1872-2000. Revista USP, v. 44, p. 218-269, 1999-2000.

A presença Guarani desde 2.000 anos atrás: contribuição para a História da ocupação humana do Paraná. In: ROLIM, R.; PELLEGRINI, S.; DIAS, R. B. (Org.). História, espaço e meio ambiente (VI Encontro Regional de História, ANPUH - PR). Maringá: ANPUH, 2000. p. 403-414.

.; O mapa arqueológico dos povos Jê no sul do Brasil. In: TOMMASINO, K.; MOTA, L.; NOELLI, F. S. (Org.). Novas contribuições aos estudos interdisciplinares dos Kaingang. Londrina: EdUEL, p. 19-55. 2004.

NOELLI, F. S.; NANNI, M.; MOTA, L.; LAVADO, M.; OLIVEIRA, E.; PANEK JR, C.; SIMÃO, A.; JERÔNIMO, F.; CASTILHO, W.; SILVA, J. Levantamento arqueológico no noroeste do Paraná, entre a foz dos rios Paranapanema e Ivaí. Revista do Museu de Arqueologia e Etnologia, n. 13, p. 313-317, 2003.

.; NOVAK, E.;DOESWIJK, A. L. Levantamento arqueológico na área da Lagoa Xambrê, município de Altônia, Paraná. Fronteiras Revista de História, v. 7, n. 13, p. 8-18, 2003.

OLIVEIRA, J. A. História da arqueologia paranaense: um balanço da produção arqueológica no estado do Paraná no período de 1876-2001. 2002. 277 f. Dissertação (Mestrado em História)
- Programa de Pós-Graduação em História, Universidade Estadual de Maringá, Maringá, 2002.

PIPERNO, D. R.; PEARSHALL, D. M. The origins of agriculture in the Lowland Neotropics. San Diego: Academic Press, 1998.

POSEY, D. A. Manejo da floresta secundária, capoeiras, campos e cerrados (Kayapó). In: RIBEIRO, D. (Ed.). Summa Etnológica Brasileira: Vol. 1 Etnobiologia. Petrópolis, 1987. p. 173-185.

PRONAPA. Brazilian archeology in 1968: An interim report on the National Program of Archeology Research - PRONAPA. American Antiquity, v. 35, n. 1, p. 1-23, 1970.

ROMAGNOLO, M. B.; SOUZA, M. C. Análise florística e estrutural de florestas ripárias do alto rio Paraná. Acta Botânica Brasileira, v. 14, n. 2, p. 163-174, 2000.

SILVA, J. B.; NOELLI, F. S. A aquisição de recursos líticos pelos ocupantes Jê da ilha do Major, Guairá, Paraná. Fronteiras, Revista de História, v. 6, n. 12, p. 113-129, 2002.

SMITH, N. J. Anthrosols and human carrying capacity in Amazonia. Annals of the Association of American Geographers, v. 70, n. 4, p. 553-566. 1980.

SOUZA, M. C.; CISLINSKI, J.; ROMAGNOLO, M. B. Levantamento florístico. In: VAZZOLER, A. E. A. M.; AGOSTINHO, A. A.; HAHN, N. S. (Ed.). A Planície de inundação do alto rio Paraná: aspectos físicos, biológicos e socioeconômicos. Maringá: Eduem, 1997. p. 345-370.

SOUZA FILHO, E.; STEVAUX, J. C. Geologia e geomorfologia do complexo rio Baía, Curutuba, Ivinheima. In:VAZZOLER, A.E. A.M.; AGOSTINHO, A. A.; HAHN, N. S. (Ed.). A Planície de inundação do alto rio Paraná: aspectos físicos, biológicos e socioeconômicos. Maringá: Eduem, 1997. p. 3-46.

STEVAUX, J. C. O rio Paraná: geomorfogênese, sedimentologia e evolução quaternária de seu curso superior. 1994. 372 f. Tese (Doutorado em Geologia) 
-Programa de Pós-Graduação em Geologia, Universidade de São Paulo, São Paulo, 1994.

.; SANTOS, M. L. Palaeohydrological changes in the upper Paraná river, Brazil, during the late Quaternary: a facies approach. In: BENITO, G.; BAKER, V. R.; GREGORY, K. J. (Ed.). Palaeohydrology and environmental change. New York: Willey, 1998. p. 273-285.
.; SOUZA FILHO, E.; JABUR, I. C. A história quaternária do rio Paraná em seu alto curso. In: VAZZOLER, A. E. A. M.; AGOSTINHO, A. A.; HAHN, N. S. (Ed.). A Planície de inundação do alto rio Paraná: aspectos físicos, biológicos e socioeconômicos. Maringá: Eduem, 1997. p. 47-72.

WATSON, V. D. Ciudad Real: A Guarani-Spanish site on the Alto Paraná. American Antiquity, v. 13, n. 2, p. 163-176, 1947.

\section{Anexo A}

Planilha 1 - Sítios Guarani apresentados no Mapa (Folhas A a E)

\begin{tabular}{|c|c|c|c|c|c|c|c|c|c|}
\hline No & Nome Sítio & Sigla & Município & Coord. & $\mathrm{No}^{\circ}$ & Nome Sítio & Sigla & Município & Coord. \\
\hline 1 & $\begin{array}{c}\text { Pesqueiro Barra- } \\
\text { gem de Rosana }\end{array}$ & PR-NL-7 & $\begin{array}{l}\text { Diamante do } \\
\text { Norte }\end{array}$ & $\begin{array}{c}22 \mathrm{~K} 308631 \\
7498636\end{array}$ & 10 & Paraná 2 & PR-PP-2 & $\begin{array}{l}\text { São Pedro } \\
\text { do Paraná }\end{array}$ & $\begin{array}{c}22 \mathrm{~K} 271119 \\
7481929\end{array}$ \\
\hline 2 & Paranapanema 1 & PR-NL-10 & $\begin{array}{c}\text { Diamante do } \\
\text { Norte }\end{array}$ & $\begin{array}{c}22 \mathrm{~K} 306662 \\
7499848\end{array}$ & 11 & Caracu 1 & PR-PP-4 & Porto Rico & $\begin{array}{c}22 \mathrm{~K} 268863 \\
7481049\end{array}$ \\
\hline 3 & Paranapanema 3 & PR-NL-13 & $\begin{array}{l}\text { Diamante do } \\
\text { Norte }\end{array}$ & $\begin{array}{c}22 \mathrm{~K} 295366 \\
7500032\end{array}$ & 12 & Caracu 2 & PR-PP-5 & Porto Rico & $\begin{array}{c}\text { 22K } 268198 \\
7480718\end{array}$ \\
\hline 4 & Paranapanema 2 & PR-NL-11 & $\begin{array}{l}\text { Diamante do } \\
\text { Norte }\end{array}$ & $\begin{array}{c}22 \mathrm{~K} 295353 \\
7500955\end{array}$ & 13 & Paraná 3 & PR-PP-6 & Porto Rico & $\begin{array}{c}22 \mathrm{~K} 266685 \\
7479441\end{array}$ \\
\hline 5 & Tigre 1 & PR-NL-9 & $\begin{array}{l}\text { Diamante do } \\
\text { Norte }\end{array}$ & $\begin{array}{c}22 \mathrm{~K} 293536 \\
7498639\end{array}$ & 14 & Água Dois 2 & PR-PP-8 & Porto Rico & $\begin{array}{c}22 \mathrm{~K} 265388 \\
7479384\end{array}$ \\
\hline 6 & Das Lanchas 2 & PR-NL-3 & $\begin{array}{c}\text { São Pedro do } \\
\text { Paraná }\end{array}$ & $\begin{array}{c}22 \mathrm{~K} 276197 \\
7485849\end{array}$ & 15 & Água Dois 1 & PR-PP-7 & Porto Rico & $\begin{array}{c}22 \mathrm{~K} 263192 \\
7480187\end{array}$ \\
\hline 7 & Paraná 1 & PR-PP-1 & $\begin{array}{c}\text { São Pedro do } \\
\text { Paraná }\end{array}$ & $\begin{array}{c}22 \mathrm{~K} 274105 \\
7483921\end{array}$ & 16 & Ivaí 2 & PR-MC-3 & $\begin{array}{c}\text { Santa Cruz } \\
\text { de Monte } \\
\text { Castelo }\end{array}$ & $\begin{array}{c}\text { 22J } 256426 \\
7427925\end{array}$ \\
\hline 8 & $\begin{array}{c}\text { Fazenda São } \\
\text { Pedro }\end{array}$ & PR-NL-1 & $\begin{array}{c}\text { São Pedro do } \\
\text { Paraná }\end{array}$ & $\begin{array}{c}22 \mathrm{~K} 272441 \\
7482781\end{array}$ & 17 & Ivaí 1 & PR-MC-4 & $\begin{array}{c}\text { Santa Cruz } \\
\text { de Monte } \\
\text { Castelo }\end{array}$ & $\begin{array}{c}22 \mathrm{~K} 256426 \\
7427925\end{array}$ \\
\hline 9 & São Pedro 1 & PR-PP-3 & $\begin{array}{c}\text { São Pedro do } \\
\text { Paraná }\end{array}$ & $\begin{array}{c}22 \mathrm{~K} 271537 \\
7482312\end{array}$ & 18 & Prata 1 & PR-MC-1 & $\begin{array}{c}\text { Santa Cruz } \\
\text { de Monte } \\
\text { Castelo }\end{array}$ & $\begin{array}{c}\text { 22J } 249748 \\
7438618\end{array}$ \\
\hline
\end{tabular}




\begin{tabular}{|c|c|c|c|c|c|c|c|c|c|}
\hline No & Nome Sítio & Sigla & Município & Coord. & No & Nome Sítio & Sigla & Município & Coord. \\
\hline 19 & Prata 2 & PR-MC-2 & $\begin{array}{c}\text { Santa Cruz } \\
\text { de Monte } \\
\text { Castelo }\end{array}$ & $\begin{array}{c}\text { 22J } 249501 \\
7438602\end{array}$ & 31 & São João 1 & PR-AL-6 & Altônia & $\begin{array}{c}22 \mathrm{~K} 198630 \\
7360372\end{array}$ \\
\hline 20 & Paraná 4 & PR-QN-7 & $\begin{array}{l}\text { Querência do } \\
\text { Norte }\end{array}$ & $\begin{array}{c}22 \mathrm{~K} 244319 \\
7466996\end{array}$ & 32 & $\begin{array}{l}\text { Córrego Suza- } \\
\text { na } 4\end{array}$ & PR-AL-7 & Altônia & $\begin{array}{c}22 \mathrm{~K} 197887 \\
7361871\end{array}$ \\
\hline 21 & Patrão 2 & PR-QN-8 & $\begin{array}{c}\text { Querência do } \\
\text { Norte }\end{array}$ & $\begin{array}{c}22 \mathrm{~K} 243747 \\
7467191\end{array}$ & 33 & $\begin{array}{l}\text { Ribeirão São } \\
\text { João } 2\end{array}$ & PR-AL-11 & Altônia & $\begin{array}{c}22 \mathrm{~K} 197807 \\
7363209\end{array}$ \\
\hline 22 & Patrão 1 & PR-QN-9 & $\begin{array}{l}\text { Querência do } \\
\text { Norte }\end{array}$ & $\begin{array}{c}22 \mathrm{~K} 242995 \\
7467824\end{array}$ & 34 & $\begin{array}{c}\text { Córrego Pontal } \\
1\end{array}$ & PR-AL-13 & Altônia & $\begin{array}{c}22 \mathrm{~K} 197655 \\
7360084\end{array}$ \\
\hline 23 & Três Morrinhos & PR-QN-6 & $\begin{array}{l}\text { Querência do } \\
\text { Norte }\end{array}$ & $\begin{array}{c}22 \mathrm{~K} 240738 \\
7466301\end{array}$ & 35 & Piquirí 1 & PR-AL-17 & Altônia & $\begin{array}{c}22 \mathrm{~K} 197530 \\
7344808\end{array}$ \\
\hline 24 & $\begin{array}{c}\text { Porto } \\
\text { Pinheirinho }\end{array}$ & PR-QN-10 & $\begin{array}{l}\text { Querência do } \\
\text { Norte }\end{array}$ & $\begin{array}{c}22 \mathrm{~K} 236550 \\
7461280\end{array}$ & 36 & $\begin{array}{c}\text { Córrego Pontal } \\
2\end{array}$ & PR-AL-14 & Altônia & $\begin{array}{c}22 \mathrm{~K} 197270 \\
7358941\end{array}$ \\
\hline 25 & Porto Natal & PR-QN-12 & $\begin{array}{l}\text { Querência do } \\
\text { Norte }\end{array}$ & $\begin{array}{c}22 \mathrm{~K} 231137 \\
7441309\end{array}$ & 37 & $\begin{array}{l}\text { Lagoa São } \\
\text { João } 1\end{array}$ & PR-AL-12 & Altônia & $\begin{array}{c}22 \mathrm{~K} 196697 \\
7362933\end{array}$ \\
\hline 26 & Bom Fim & PR-QN-13 & $\begin{array}{l}\text { Querência do } \\
\text { Norte }\end{array}$ & $\begin{array}{c}22 \mathrm{~K} 229278 \\
7435420\end{array}$ & 38 & $\begin{array}{c}\text { Córrego Suza- } \\
\text { na } 5\end{array}$ & PR-AL-16 & Altônia & $\begin{array}{c}22 \mathrm{~K} 196428 \\
7361881\end{array}$ \\
\hline 27 & & PR-IC-1 & Vila Alta & $\begin{array}{c}22 \mathrm{~K} 217500 \\
7412282\end{array}$ & 39 & $\begin{array}{c}\text { Rancho Velho } \\
1\end{array}$ & PR-AL-15 & Altônia & $\begin{array}{c}22 \mathrm{~K} 196032 \\
7360948\end{array}$ \\
\hline 28 & Córrego Suzana 1 & PR-AL-4 & Altônia & $\begin{array}{c}22 \mathrm{~K} 199082 \\
7359749\end{array}$ & 40 & $\begin{array}{c}\text { Córrego da } \\
\text { Lagoa } 2\end{array}$ & PR-AL-9 & Altônia & $\begin{array}{c}22 \mathrm{~K} 195884 \\
7355916\end{array}$ \\
\hline 29 & Córrego Suzana 2 & PR-AL-5 & Altônia & $\begin{array}{c}22 \mathrm{~K} 198922 \\
7359988\end{array}$ & 41 & $\begin{array}{l}\text { Córrego } \\
\text { Pipoca } 1\end{array}$ & PR-AL-1 & Altônia & $\begin{array}{c}22 \mathrm{~K} 195446 \\
7358776\end{array}$ \\
\hline 30 & $\begin{array}{l}\text { Ribeirão São } \\
\text { João } 1\end{array}$ & PR-AL-10 & Altônia & $\begin{array}{c}22 \mathrm{~K} 198853 \\
7362453\end{array}$ & 42 & $\begin{array}{l}\text { Córrego Suza- } \\
\text { na } 3\end{array}$ & PR-AL-8 & Altônia & $\begin{array}{c}22 \mathrm{~K} 195157 \\
7355165\end{array}$ \\
\hline No & Nome Sítio & Sigla & Município & Coord. & No & Nome Sítio & Sigla & Município & Coord. \\
\hline 43 & $\begin{array}{c}\text { Lagoa Xambrê } 1 \text { / } \\
\text { Xamberê } 1\end{array}$ & PR-XA-1 & Altônia & $\begin{array}{c}22 \mathrm{~K} 195141 \\
7358028\end{array}$ & 54 & $\begin{array}{l}\text { Ilha do Ale- } \\
\text { mão } 1\end{array}$ & PR-FO-24 & Guaíra & $\begin{array}{c}21 \mathrm{~J} 785020 \\
7335128\end{array}$ \\
\hline 44 & $\begin{array}{c}\text { Fazenda Roque } \\
\text { Morais }\end{array}$ & & Altônia & $\begin{array}{c}21 \mathrm{~K} 804574 \\
7351743\end{array}$ & 55 & Arroio Taturí 1 & PR-FO-16 & Guaíra & $\begin{array}{c}\text { 21J } 782661 \\
7301099\end{array}$ \\
\hline 45 & Fazenda Kikuta & & Altônia & $\begin{array}{c}21 \mathrm{~K} 804298 \\
7352087\end{array}$ & 56 & $\begin{array}{l}\text { Parque das } \\
\text { Sete Quedas }\end{array}$ & PR-FO-37 & Guaíra & $\begin{array}{c}\text { 21J } 782342 \\
7333919\end{array}$ \\
\hline 46 & Porto Yara & PR-AL-2 & Altônia & $\begin{array}{c}21 \mathrm{~K} 803023 \\
7349088\end{array}$ & 57 & $\begin{array}{c}\text { Rio São } \\
\text { Francisco } \\
\text { Verdadeiro } 4\end{array}$ & PR-TO-13 & $\begin{array}{l}\text { Entre Rios } \\
\text { do Oeste }\end{array}$ & $\begin{array}{c}\text { 21J } 781793 \\
7266755\end{array}$ \\
\hline 47 & Fazenda Pontal 1 & PR-AL-3 & Altônia & $\begin{array}{c}21 \mathrm{~K} 800113 \\
7344498\end{array}$ & 58 & $\begin{array}{c}\text { Rio São } \\
\text { Francisco } \\
\text { Verdadeiro } 9\end{array}$ & PR-TO-21 & $\begin{array}{l}\text { Pato Bra- } \\
\text { gado }\end{array}$ & $\begin{array}{c}\text { 21J } 781764 \\
7266949\end{array}$ \\
\hline 48 & $\begin{array}{c}\text { Ciudad Real del } \\
\text { Guaira }\end{array}$ & PR-FO-1 & Terra Roxa & $\begin{array}{c}\text { 21J } 795604 \\
7339354\end{array}$ & 59 & $\begin{array}{c}\text { Rio São } \\
\text { Francisco Ver- } \\
\text { dadeiro } 19\end{array}$ & & $\begin{array}{c}\text { Pato } \\
\text { Bragado }\end{array}$ & $\begin{array}{c}21 \mathrm{~J} 781467 \\
7267150\end{array}$ \\
\hline 49 & $\begin{array}{l}\text { Fazenda Açu } \\
\text { Piquiri } 1\end{array}$ & & Terra Roxa & $\begin{array}{c}\text { 21J } 795595 \\
7326208\end{array}$ & 60 & $\begin{array}{c}\text { Rio São } \\
\text { Francisco } \\
\text { Verdadeiro } 7\end{array}$ & PR-TO-19 & $\begin{array}{l}\text { Pato Bra- } \\
\text { gado }\end{array}$ & $\begin{array}{c}\text { 21J } 781453 \\
7267160\end{array}$ \\
\hline 50 & Água Pequena 2 & PR-FO-55 & Terra Roxa & $\begin{array}{c}21 \mathrm{~J} 795164 \\
7337995\end{array}$ & 61 & $\begin{array}{l}\text { Córrego do } \\
\text { Meio }\end{array}$ & PR-FO-34 & Guaíra & $\begin{array}{c}21 \mathrm{~J} 781275 \\
7334268\end{array}$ \\
\hline 51 & Água Pequena 1 & PR-FO-53 & Terra Roxa & $\begin{array}{c}21 \mathrm{~J} 794744 \\
7338393\end{array}$ & 62 & Ilha Pacu & PR-FO-35 & Guaíra & $\begin{array}{c}21 \mathrm{~J} 780822 \\
7336978\end{array}$ \\
\hline 52 & Fonte Grande & PR-FO-54 & Terra Roxa & $\begin{array}{c}21 \mathrm{~J} 794217 \\
7338233\end{array}$ & 63 & Estaleiro 4 & PR-FO-46 & Guaíra & $\begin{array}{c}21 \mathrm{~J} 780720 \\
7335358\end{array}$ \\
\hline 53 & $\begin{array}{l}\text { Clube dos } \\
\text { Pescadores }\end{array}$ & PR-FO-56 & Terra Roxa & $\begin{array}{c}21 J 792202 \\
7337372\end{array}$ & & & & & \\
\hline
\end{tabular}




\begin{tabular}{|c|c|c|c|c|c|c|c|c|c|}
\hline $\mathrm{N}^{\circ}$ & Nome Sítio & Sigla & Município & Coord. & No & Nome Sítio & Sigla & Município & Coord. \\
\hline 64 & $\begin{array}{c}\text { Rio São Francisco } \\
\text { Verdadeiro } 8\end{array}$ & PR-TO-20 & $\begin{array}{c}\text { Pato } \\
\text { Bragado }\end{array}$ & $\begin{array}{c}21 \mathrm{~J} 780701 \\
7267423\end{array}$ & 76 & Prainha 3 & PR-FO-39 & Guaíra & $\begin{array}{c}21 \mathrm{~J} 777740 \\
7334515\end{array}$ \\
\hline 65 & Estaleiro 2 & PR-FO-43 & Guaíra & $\begin{array}{c}21 \mathrm{~J} 780374 \\
7335237\end{array}$ & 77 & $\begin{array}{c}\text { Sete Que- } \\
\text { das } 3\end{array}$ & PR-FO-4 & Guaíra & $\begin{array}{c}21 \mathrm{~J} 777618 \\
7333780\end{array}$ \\
\hline 66 & $\begin{array}{c}\text { Rio São Francisco } \\
\text { Verdadeiro } 5\end{array}$ & PR-TO-17 & $\begin{array}{c}\text { Pato } \\
\text { Bragado }\end{array}$ & $\begin{array}{c}21 \mathrm{~J} 780333 \\
7267486\end{array}$ & 78 & Prainha 2 & PR-FO-38 & Guaíra & $\begin{array}{c}21 \mathrm{~J} 777613 \\
7334517\end{array}$ \\
\hline 67 & $\begin{array}{c}\text { Rio São Francisco } \\
\text { Verdadeiro } 2\end{array}$ & PR-TO-9 & $\begin{array}{c}\text { Entre Rios do } \\
\text { Oeste }\end{array}$ & $\begin{array}{c}21 \mathrm{~J} 780033 \\
7266879\end{array}$ & 79 & Sete Quedas 5 & PR-FO-6 & Guaíra & $\begin{array}{c}21 \mathrm{~J} 777595 \\
7334020\end{array}$ \\
\hline 68 & Arroio Guaçu 2 & PR-TO-65 & Mercedes & $\begin{array}{c}\text { 21J } 779562 \\
7300386\end{array}$ & 80 & Prainha 1 & PR-FO-33 & Guaíra & $\begin{array}{c}21 \mathrm{~J} 777474 \\
7334546\end{array}$ \\
\hline 69 & Corredeira 5 & PR-TO-64 & Mercedes & $\begin{array}{c}21 \mathrm{~J} 779241 \\
7300189\end{array}$ & 81 & Prainha 4 & PR-FO-40 & Guaíra & $\begin{array}{c}21 \mathrm{~J} 777414 \\
7334418\end{array}$ \\
\hline 70 & Missal 1 & & Missal & $\begin{array}{c}21 J 778529 \\
7226950\end{array}$ & 82 & Fernandez 2 & PR-FO-19 & Guaíra & $\begin{array}{c}21 \mathrm{~J} 777405 \\
7301160\end{array}$ \\
\hline 71 & Marina 1 & PR-FO-47 & Guaíra & $\begin{array}{c}21 \mathrm{~J} 778297 \\
7334740\end{array}$ & 83 & Sete Quedas 2 & PR-FO-3 & Guaíra & $\begin{array}{c}21 \mathrm{~J} 777352 \\
7333746\end{array}$ \\
\hline 72 & Marina 2 & PR-FO-48 & Guaíra & $\begin{array}{c}21 \mathrm{~J} 778117 \\
7334701\end{array}$ & 84 & $\begin{array}{c}\text { Rio } \\
\text { Carumbeí } 3\end{array}$ & PR-FO-29 & Guaíra & $\begin{array}{c}21 \mathrm{~J} 777279 \\
7332639\end{array}$ \\
\hline 73 & Ilha do Major 2 & PR-FO-60 & Guaíra & $\begin{array}{c}21 \mathrm{~J} 778023 \\
7335026\end{array}$ & 85 & $\begin{array}{l}\text { Rio Carum- } \\
\text { beí } 4\end{array}$ & PR-FO-30 & Guaíra & $\begin{array}{c}21 \mathrm{~J} 776788 \\
7332494\end{array}$ \\
\hline 74 & Sete Quedas 6 & PR-FO-7 & Guaíra & $\begin{array}{c}\text { 21J } 777916 \\
7334581\end{array}$ & 86 & $\begin{array}{c}\text { Barra Sanga } \\
\text { Alegre } 1 / \\
\text { Barra da } \\
\text { Sanga Alegre }\end{array}$ & PR-TO-62 & Mercedes & $\begin{array}{c}21 J 776689 \\
7299860\end{array}$ \\
\hline 75 & Fernandez 1 & PR-FO-10 & Guaíra & $\begin{array}{c}\text { 21J } 777853 \\
7301081\end{array}$ & 87 & Rio Zororó 1 & PR-FO-12 & Guaíra & $\begin{array}{c}21 \mathrm{~J} 776541 \\
7312701\end{array}$ \\
\hline $\mathrm{N}^{\circ}$ & Nome Sítio & Sigla & Município & Coord. & No & Nome Sítio & Sigla & Município & Coord. \\
\hline 88 & Rio Carumbeí & PR-FO-27 & Guaíra & $\begin{array}{c}\text { 21J } 776310 \\
7332081\end{array}$ & 98 & Arroio Taturí 2 & PR-FO-25 & Guaíra & $\begin{array}{c}21 \mathrm{~J} 773270 \\
7330981\end{array}$ \\
\hline 89 & Ilha do Valêncio & PR-FO-52 & Guaíra & $\begin{array}{c}21 J 776236 \\
7333796\end{array}$ & 99 & Arroio Taturí 3 & PR-FO-26 & Guaíra & $\begin{array}{c}21 \mathrm{~J} 773001 \\
7331202\end{array}$ \\
\hline 90 & Rio Zororó 2 & PR-FO-13 & Guaíra & $\begin{array}{c}21 \mathrm{~J} 776113 \\
7313069\end{array}$ & 100 & $\begin{array}{c}\text { Córrego do } \\
\text { Bananal }\end{array}$ & PR-FO-15 & Guaíra & $\begin{array}{c}21 \mathrm{~J} 772727 \\
7322391\end{array}$ \\
\hline 91 & Japu 1 & PR-FO-31 & Guaíra & $\begin{array}{c}21 \mathrm{~J} 776016 \\
7333365\end{array}$ & 101 & Vale Seco 1 & PR-TO-53 & $\begin{array}{l}\text { Marechal } \\
\text { Cândido } \\
\text { Rondon }\end{array}$ & $\begin{array}{c}21 \mathrm{~J} 772094 \\
7293188\end{array}$ \\
\hline 92 & Viveiro Florestal & PR-FO-51 & Guaíra & $\begin{array}{c}\text { 21J } 775944 \\
7332333\end{array}$ & 102 & $\begin{array}{l}\text { Arroio Pe- } \\
\text { queno }\end{array}$ & PR-TO-52 & $\begin{array}{l}\text { Marechal } \\
\text { Cândido } \\
\text { Rondon }\end{array}$ & $\begin{array}{c}21 \mathrm{~J} 772090 \\
7292444\end{array}$ \\
\hline 93 & Rio Zororó 3 & PR-FO-14 & Guaíra & $\begin{array}{c}\text { 21J } 775714 \\
7312321\end{array}$ & 103 & Vale Seco 2 & PR-TO-54 & $\begin{array}{l}\text { Marechal } \\
\text { Cândido } \\
\text { Rondon }\end{array}$ & $\begin{array}{c}21 \mathrm{~J} 772062 \\
7292954\end{array}$ \\
\hline 94 & $\begin{array}{c}\text { Morro do Cone } \\
\text { Truncado }\end{array}$ & PR-TO-59 & $\begin{array}{l}\text { Marechal } \\
\text { Cândido } \\
\text { Rondon }\end{array}$ & $\begin{array}{c}21 \mathrm{~J} 774511 \\
7295594\end{array}$ & 104 & Grande Ilha & PR-FO-20 & Guaíra & $\begin{array}{c}21 \mathrm{~J} 772029 \\
7318274\end{array}$ \\
\hline 95 & Lagoa Comprida & PR-TO-58 & $\begin{array}{l}\text { Marechal } \\
\text { Cândido } \\
\text { Rondon }\end{array}$ & $\begin{array}{c}\text { 21J } 774155 \\
7295701\end{array}$ & 105 & $\begin{array}{c}\text { Rápidos de } \\
\text { Santa Maria } 2\end{array}$ & PR-FO-18 & Guaíra & $\begin{array}{c}21 \mathrm{~J} 771970 \\
7321380\end{array}$ \\
\hline 96 & Sanga Porvenir 2 & PR-TO-57 & $\begin{array}{l}\text { Marechal } \\
\text { Cândido } \\
\text { Rondon }\end{array}$ & $\begin{array}{c}21 \mathrm{~J} 773828 \\
7295236\end{array}$ & 106 & $\begin{array}{c}\text { Salto } \\
\text { Lajeado São } \\
\text { Cristovão }\end{array}$ & $\begin{array}{c}\text { PR- } \\
\text { TO-50 }\end{array}$ & $\begin{array}{l}\text { Marechal } \\
\text { Cândido } \\
\text { Rondon }\end{array}$ & $\begin{array}{c}21 \mathrm{~J} 771960 \\
7292374\end{array}$ \\
\hline 97 & Sanga Porvenir 1 & PR-TO-56 & $\begin{array}{l}\text { Marechal } \\
\text { Cândido } \\
\text { Rondon }\end{array}$ & $\begin{array}{c}21 \mathrm{~J} 773549 \\
7294855\end{array}$ & 107 & $\begin{array}{c}\text { Barra do } \\
\text { Lajedo São } \\
\text { Cristovão }\end{array}$ & PR-TO-51 & $\begin{array}{l}\text { Marechal } \\
\text { Cândido } \\
\text { Rondon }\end{array}$ & $\begin{array}{c}21 J 771896 \\
7292719\end{array}$ \\
\hline
\end{tabular}




\begin{tabular}{|c|c|c|c|c|c|c|c|c|c|}
\hline $\mathrm{N}^{\circ}$ & Nome Sítio & Sigla & Município & Coord. & $\mathrm{N}^{\circ}$ & Nome Sítio & Sigla & Município & Coord. \\
\hline 108 & Porto Mendes & PR-TO-55 & $\begin{array}{l}\text { Marechal } \\
\text { Cândido } \\
\text { Rondon }\end{array}$ & $\begin{array}{c}21 J 771285 \\
7291293\end{array}$ & 121 & $\begin{array}{l}\text { Parque Nacio- } \\
\text { nal do Iguaçu } 5\end{array}$ & PNI-5 & $\begin{array}{l}\text { Foz do } \\
\text { Iguaçu }\end{array}$ & $\begin{array}{c}21 \mathrm{~J} 766315 \\
7166627\end{array}$ \\
\hline 109 & Pomar & PR-FO-22 & Guaíra & $\begin{array}{c}21 J 771225 \\
7329969\end{array}$ & 122 & $\begin{array}{l}\text { Parque Nacio- } \\
\text { nal do Iguaçu } 4\end{array}$ & PNI-4 & $\begin{array}{l}\text { Foz do } \\
\text { Iguaçu }\end{array}$ & $\begin{array}{c}21 J 766244 \\
7165976\end{array}$ \\
\hline 110 & Porto Britânia 2 & PR-TO-47 & Pato Bragado & $\begin{array}{c}21 J 770844 \\
7270329\end{array}$ & 123 & $\begin{array}{l}\text { Rio São Fran- } \\
\text { cisco Falso } 2\end{array}$ & PR-FI-113 & Santa Helena & $\begin{array}{c}21 \mathrm{~J} 766155 \\
7258674\end{array}$ \\
\hline 111 & Córrrego Pacitá & PR-FO-21 & Guaíra & $\begin{array}{c}21 J 770439 \\
7326984\end{array}$ & 124 & $\begin{array}{c}\text { Lagoa Seca / } \\
\text { Rio Guabiroba } 1\end{array}$ & PR-FI-118 & Santa Helena & $\begin{array}{c}21 \mathrm{~J} 765915 \\
7256699\end{array}$ \\
\hline 112 & Petrônio Cuê & PR-TO-44 & $\begin{array}{c}\text { Pato } \\
\text { Bragado }\end{array}$ & $\begin{array}{c}21 J 770365 \\
7273411\end{array}$ & 125 & Trigal 1 & PR-FI-114 & Santa Helena & $\begin{array}{c}21 \mathrm{~J} 764924 \\
7257771\end{array}$ \\
\hline 113 & Porto Britânia 1 & PR-TO-45 & Pato Bragado & $\begin{array}{c}21 \mathrm{~J} 769841 \\
7271246\end{array}$ & 126 & Carretão & PR-FI-115 & Santa Helena & $\begin{array}{c}21 J 764659 \\
7257551\end{array}$ \\
\hline 114 & Córrego do Meio 3 & PR-TO-2 & Santa Helena & $\begin{array}{c}21 \mathrm{~J} 769772 \\
7255452\end{array}$ & 127 & Cafezal 1 & PR-FI-116 & $\begin{array}{l}\text { Santa } \\
\text { Helena }\end{array}$ & $\begin{array}{c}21 \mathrm{~J} 764417 \\
7257009\end{array}$ \\
\hline 115 & $\begin{array}{c}\text { Córrego } \\
\text { Caminho Verde } 2\end{array}$ & PR-FI-110 & Santa Helena & $\begin{array}{c}21 \mathrm{~J} 769757 \\
7253054\end{array}$ & 128 & Trigal 2 & PR-FI-117 & Santa Helena & $\begin{array}{c}21 \mathrm{~J} 763955 \\
7255682\end{array}$ \\
\hline 116 & Córrego do Meio 1 & PR-TO-1 & Santa Helena & $\begin{array}{c}21 \mathrm{~J} 769416 \\
7255717\end{array}$ & 129 & Porto Verde & PR-FI-119 & Santa Helena & $\begin{array}{c}21 J 763472 \\
7254186\end{array}$ \\
\hline 117 & Fazenda Caburé 2 & PR-TO-7 & Santa Helena & $\begin{array}{c}21 J 767929 \\
7260260\end{array}$ & 130 & $\begin{array}{l}\text { Parque Nacio- } \\
\text { nal do Iguaçu } 2\end{array}$ & PNI-2 & $\begin{array}{l}\text { Foz do } \\
\text { Iguaçu }\end{array}$ & $\begin{array}{c}21 J 762747 \\
7166833\end{array}$ \\
\hline 118 & Fazenda Caburé 1 & PR-TO-6 & Santa Helena & $\begin{array}{c}21 \mathrm{~J} 767212 \\
7259941\end{array}$ & 131 & da Mata & PR-FI-120 & Santa Helena & $\begin{array}{c}21 \mathrm{~J} 761973 \\
7249702\end{array}$ \\
\hline 119 & Lageado Progresso & PR-TO-4 & Santa Helena & $\begin{array}{c}21 \mathrm{~J} 766955 \\
7258599\end{array}$ & 132 & Caranguejeiras & PR-FI-148 & $\begin{array}{l}\text { Foz do } \\
\text { Iguaçu }\end{array}$ & $\begin{array}{c}21 \mathrm{~J} 761508 \\
7205101\end{array}$ \\
\hline 120 & $\begin{array}{c}\text { Rio São Francisco } \\
\text { Falso } 1\end{array}$ & PR-FI-112 & Santa Helena & $\begin{array}{c}\text { 21J } 766423 \\
7258572\end{array}$ & 133 & $\begin{array}{l}\text { Rio Dois } \\
\text { Irmãos }\end{array}$ & PR-FI-122 & Santa Helena & $\begin{array}{c}21 \mathrm{~J} 761485 \\
7246702\end{array}$ \\
\hline $\mathrm{N}^{\circ}$ & Nome Sítio & Sigla & Município & Coord. & $\mathrm{N}^{\circ}$ & Nome Sítio & Sigla & Município & Coord. \\
\hline 134 & Rio Ocoí 3 & PR-FI-149 & Foz do Iguaçu & $\begin{array}{c}\text { 21J } 761126 \\
7204817\end{array}$ & 147 & $\begin{array}{c}\text { Fazenda Dona } \\
\text { Carlota } 4\end{array}$ & PR-FI-142 & Itaipulândia & $\begin{array}{c}\text { 21J } 755448 \\
7210168\end{array}$ \\
\hline 135 & Areal 1 & PR-FI-125 & Santa Helena & $\begin{array}{c}21 \mathrm{~J} 761072 \\
7244506\end{array}$ & 148 & Pesqueiro 1 & PR-FI-105 & Itaipulândia & $\begin{array}{c}21 \mathrm{~J} 755326 \\
7210262\end{array}$ \\
\hline 136 & Areal 2 & PR-FI-126 & Santa Helena & $\begin{array}{c}21 \mathrm{~J} 761033 \\
7244318\end{array}$ & 149 & $\begin{array}{l}\text { Fazenda Dona } \\
\text { Carlota } 2\end{array}$ & PR-FI-140 & Itaipulândia & $\begin{array}{c}21 J 755168 \\
7209810\end{array}$ \\
\hline 137 & Rio Mingau & PR-FI-13 & Foz do Iguaçu & $\begin{array}{c}\text { 21J } 760162 \\
7161613\end{array}$ & 150 & $\begin{array}{c}\text { Fazenda } \\
\text { Dona Carlota } \\
1\end{array}$ & PR-FI-104 & Itaipulândia & $\begin{array}{c}21 \mathrm{~J} 755110 \\
7209596\end{array}$ \\
\hline 138 & Cafezal & PR-FI-127 & Santa Helena & $\begin{array}{c}21 J 759777 \\
7240153\end{array}$ & 151 & Paineira & PR-FI-103 & Itaipulândia & $\begin{array}{c}21 \mathrm{~J} 755065 \\
7209415\end{array}$ \\
\hline 139 & $\begin{array}{c}\text { Fazenda Água } \\
\text { Grande } 3\end{array}$ & PR-FI-146 & Itaipulândia & $\begin{array}{c}21 \mathrm{~J} 758445 \\
7213618\end{array}$ & 152 & Borevi 1 & PR-FI-99 & $\begin{array}{l}\text { Foz do } \\
\text { Iguaçu }\end{array}$ & $\begin{array}{c}21 J 752185 \\
7200749\end{array}$ \\
\hline 140 & $\begin{array}{c}\text { Fazenda Água } \\
\text { Grande } 2\end{array}$ & PR-FI-144 & Itaipulândia & $\begin{array}{c}21 \mathrm{~J} 757906 \\
7213700\end{array}$ & 153 & Borevi 2 & PR-FI-100 & $\begin{array}{l}\text { Foz do } \\
\text { Iguaçu }\end{array}$ & $\begin{array}{c}21 \mathrm{~J} 752095 \\
7200644\end{array}$ \\
\hline 141 & $\begin{array}{l}\text { Cataratas do } \\
\text { Iguaçu }\end{array}$ & PR-FI-8 & Foz do Iguaçu & $\begin{array}{c}21 J 757696 \\
7159086\end{array}$ & 154 & Porto Estamata & PR-FI-98 & $\begin{array}{l}\text { Foz do } \\
\text { Iguaçu }\end{array}$ & $\begin{array}{c}\text { 21J } 752072 \\
7200438\end{array}$ \\
\hline 142 & Palmeira & PR-FI-107 & Itaipulândia & $\begin{array}{c}\text { 21J } 757598 \\
7220462\end{array}$ & 155 & Taguapelagai & PR-FI-97 & $\begin{array}{l}\text { Foz do } \\
\text { Iguaçu }\end{array}$ & $\begin{array}{c}21 \mathrm{~J} 751981 \\
7200289\end{array}$ \\
\hline 143 & $\begin{array}{l}\text { Parque Nacional } \\
\text { do Iguaçu } 1\end{array}$ & PNI-1 & $\begin{array}{l}\text { Foz do } \\
\text { Iguaçu }\end{array}$ & $\begin{array}{c}\text { 21J } 757584 \\
7158676\end{array}$ & 156 & Taguapelagai & PR-FI-97 & $\begin{array}{l}\text { Foz do } \\
\text { Iguaçu }\end{array}$ & $\begin{array}{c}21 \mathrm{~J} 751981 \\
7200289\end{array}$ \\
\hline 144 & $\begin{array}{c}\text { Fazenda Água } \\
\text { Grande } 1\end{array}$ & PR-FI-143 & Itaipulândia & $\begin{array}{c}21 \mathrm{~J} 757580 \\
7213502\end{array}$ & 157 & Figueira 2 & PR-FI-79 & $\begin{array}{l}\text { Foz do } \\
\text { Iguaçu }\end{array}$ & $\begin{array}{c}21 \mathrm{~J} 750498 \\
7183673\end{array}$ \\
\hline 145 & $\begin{array}{c}\text { Fazenda Dona } \\
\text { Carlota } 3\end{array}$ & PR-FI-141 & Itaipulândia & $\begin{array}{c}21 \mathrm{~J} 755532 \\
7210117\end{array}$ & 158 & Dois Córregos & PR-FI-95 & $\begin{array}{l}\text { Foz do } \\
\text { Iguaçu }\end{array}$ & $\begin{array}{c}21 \mathrm{~J} 748612 \\
7195555\end{array}$ \\
\hline 146 & Pesqueiro 2 & PR-FI-106 & Itaipulândia & $\begin{array}{c}21 \mathrm{~J} 755464 \\
7210327\end{array}$ & 159 & Assuna & PR-FI-96 & $\begin{array}{l}\text { Foz do } \\
\text { Iguaçu }\end{array}$ & $\begin{array}{c}21 \mathrm{~J} 748282 \\
7195282\end{array}$ \\
\hline
\end{tabular}




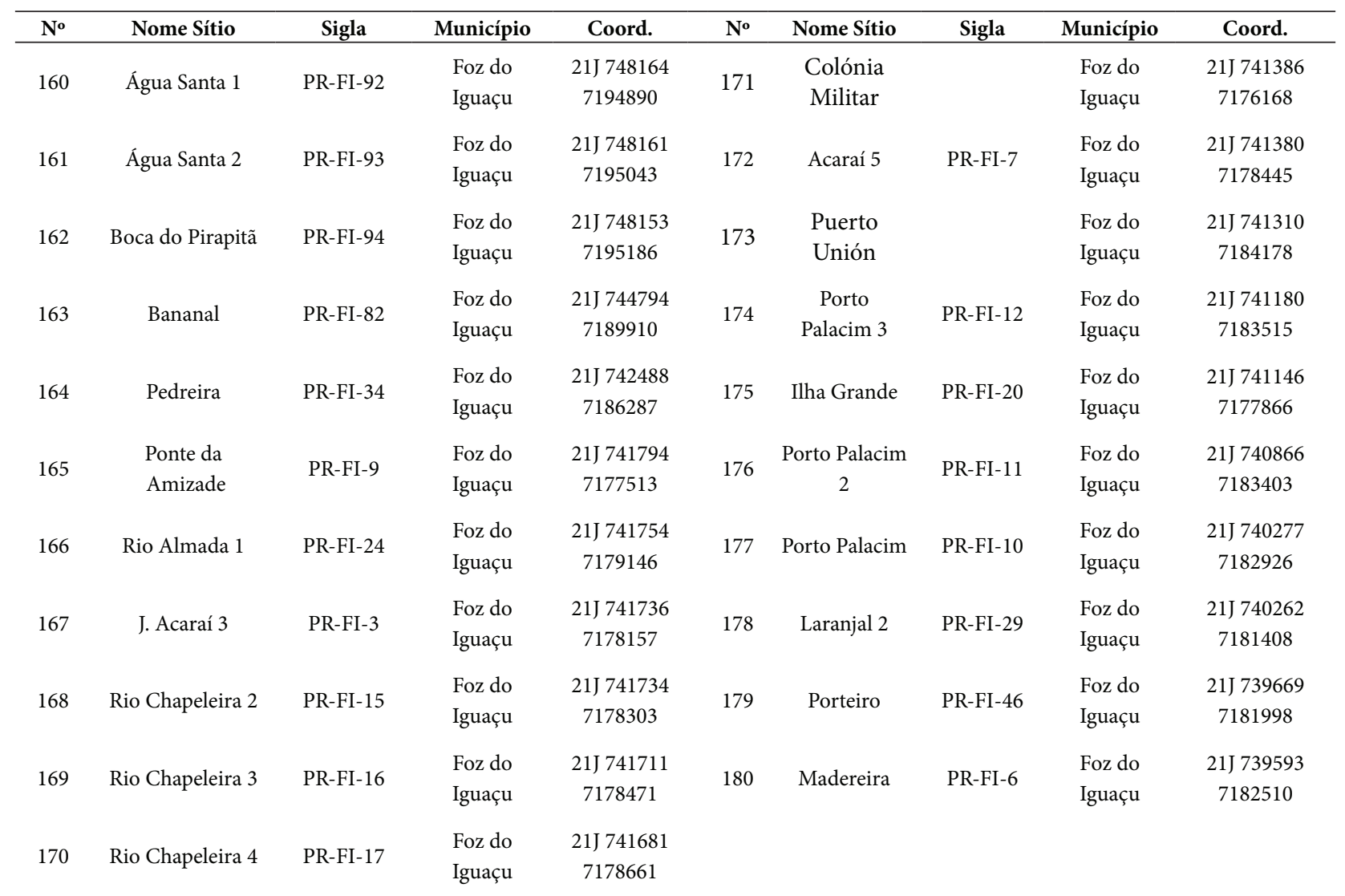

